\title{
LAS INDUSTRIAS LÍTICAS DE LA GRUTA NOVA DE COLUMBEIRA (BOMBARRAL, PORTUGAL) EN EL CONTEXTO DEL MUSTERIENSE FINAL DE LA PENÍNSULA IBÉRICA

\author{
THE LITHIC INDUSTRIES OF GRUTA NOVA \\ DE COLUMBEIRA (BOMBARRAL, \\ PORTUGAL) IN THE CONTEXT OF THE LATE \\ MOUSTERIAN OF THE IBERIAN PENINSULA
}

\author{
LUÍS RAPOSO $(*)$ \\ JOÃO LUÍS CARDOSO (**)
}

\section{RESUMEN}

La Gruta Nova de Columbeira, descubierta en 1962, constituye uno de los más importantes sitios del Paleolítico Medio en Portugal. La industria lítica, que aquí se caracteriza por primera vez, puede describirse genéricamente como un Musteriense de denticulados rico en raederas, de talla y facies levallois, sin signo alguno que la aproxime a patrones asimilables al Paleolítico Superior.

Dos dataciones C14 de los dos niveles de ocupación humana de la base de la secuencia $(28900 \pm 900$ y 26400 $\pm 750 \mathrm{BP}$ ) confieren un interés especial a esta localidad, que se incluye en el conjunto de casi dos decenas de sitios ibéricos (sur de España y Portugal) en que fué comprobada la subsistencia del Musteriense y de los neandertales hasta incluso después de 30000 BP. Se plantea una argumentación paleobiogeográfica para explicar este fenómeno, en el cuadro de la evolución histórica documentada en las tres penínsulas meridionales (ibérica, itálica y balcánica) del continente europeo.

\footnotetext{
ABSTRACT

Gruta Nova de Columbeira, discovered in 1962, is one of the most important Middle Palaeolithic sites in Portu-

(1) Traducción de Manuel Santonja. Museo Provincial de Salamanca.

(*) Museu Nacional de Arqueologia. Praça do Império. 1400 Lisboa, Portugal.

(**) Academia Portuguesa da História. Centro de Estudos Arqueológicos do Concelho de Oeiras. Câmara Municipal de Oeiras. 2780 Oeiras. Portugal.

El artículo fue remitido en su versión final el 5-12-97.
}

gal. The lithic industry, here described for the first time, may be described in general terms as a Denticulate Mousterian of Levallois facies rich in sidescrapers and it bears no resemblance to the Upper Palaeolithic.

Two $14 \mathrm{C}$ dates $(28900 \pm 900$ and $26400 \pm 750 \mathrm{BP})$ from the two human occupations at the base of the stratigraphic sequence confer a particular interest to this site. It is among almost twenty others in southern Spain and Portugal in which Mousterian industries and Neanderthal sekeletal remains persist even after 30000 BP. This article presents a biogeographical explanation of this phenomenon in the context of the historical evolution documented in the three southern peninsulae of Europe (Iberia, Italy, and the Balkans).

Palabras clave: Paleolítico Medio portugués. Musteriense Final ibérico. Neandertales. Transición Paleolítico Medio/Paleolítico Superior.

Key words: Portuguese Middle Palaeolithic. Iberian Final Mousterian. Neandertals. Middle/Upper Palaeolithic transition.

\section{INTRODUCCIÓN}

Se conocen actualmente en Portugal cerca de una decena de cuevas con ocupaciones humanas atribuibles al Paleolítico Medio, así como algunos sitios al aire libre con elementos de datación o industrias líticas suficientemente diagnósticas que 
pueden atribuirse con seguridad al mismo período (Raposo, 1993a, b y 1995). De este conjunto de sitios, solamente tres han proporcionado restos antropológicos, en todos los casos asignados a Homo sapiens neanderthalensis: la Gruta de Figueira Brava, identificada en 1982, excavada entre 1986 y 1990 y objeto ya entonces de una primera publicación importante (Antunes, 1990-91); la Gruta de las Fuentes del Almonda (hallazgos recientes, aún inéditos) y la Gruta Nova de Columbeira, descubierta y excavada casi completamente en 1962, aunque hasta ahora no se ha publicado de manera extensa.

Esta gruta se sitúa en las proximidades de la aldea de Columbeira, concejo de Bombarral (Estre-

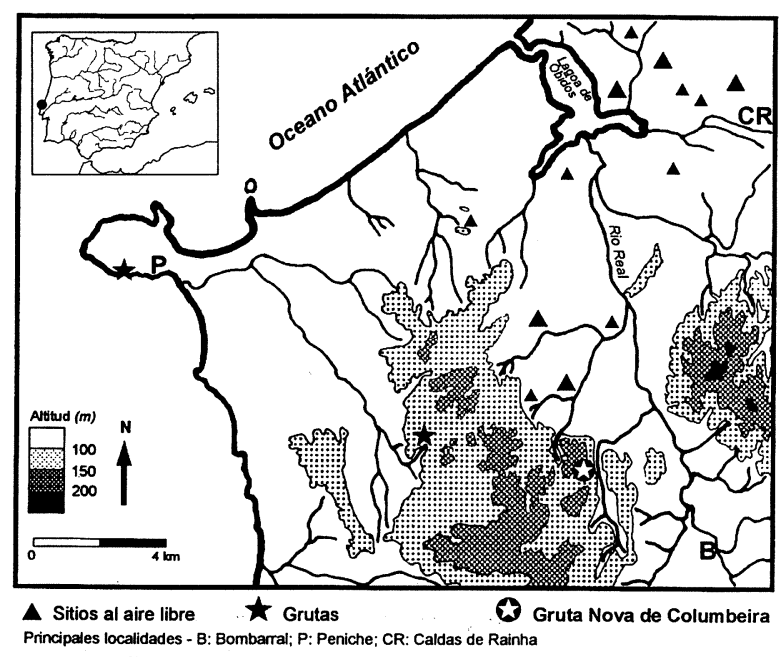

Fig. 1. Mapa de localización de la Gruta Nova de Columbeira. madura portuguesa), aproximadamente a una decena de kilómetros del Océano Atlántico (Fig. 1). La existencia de ocupaciones humanas en la cavidad fue reconocida fortuitamente, a consecuencia de los trabajos con vistas a una eventual explotación turística. Advertidos los profesionales de los Servicios Geológicos de Portugal, se decidió una excavación arqueológica, que tuvo lugar en Agosto de 1962, siendo dirigida por Octavio da Veiga Ferreira.

La abundancia de industrias líticas y su exclusiva atribución al Musteriense, la riqueza de las asociaciones faunísticas, la distribución de ambas a lo largo de un importante relleno sedimentario, y finalmente el hallazgo de un resto humano (un fragmento de molar inferior izquierdo, encontrado a techo del nivel 9, en contacto con el nivel 7, en un sector en que localmente desaparecía el nivel 8: Ferreira, 1966: 371), cuya atribución al Hombre de Neandertal sería confirmada por Denise Ferembach (1964-65), todo contribuyó a que los primeros excavadores, conscientes de la importancia del sitio, dieran noticia del mismo en sucesivas notas breves, sobre la secuencia estratigráfica (con algunas discrepancias, pero aparentemente fijada en la relación que presentamos en la tabla 1), la lista faunística (Tab. 2) y algunas características tipológicas de las industrias líticas. Más tarde, en 1971, Jean Roche, que habría conseguido entretanto obtener dos dataciones radiocarbónicas de carbones procedentes de los niveles 8 y 7 , regularizó el testigo sedimentario que se había dejado, realizando nuevos levantamientos estratigráficos, que nunca llegó a publicar.

\begin{tabular}{|c|c|c|c|c|c|c|}
\hline \multirow{2}{*}{ Nivel } & \multirow{2}{*}{ Descripción } & \multirow{2}{*}{$\begin{array}{c}\text { Potencia } \\
(\mathrm{cm})\end{array}$} & \multirow{2}{*}{ Carbón } & \multicolumn{2}{|c|}{ Fauna } & \multirow{2}{*}{$\begin{array}{c}\text { Artefactos } \\
\text { líticos }\end{array}$} \\
\hline & & & & (1) & (2) & \\
\hline N. 1 & Nivel estalagmítico & $1-2$ & & & & \\
\hline N. 2 & $\begin{array}{l}\text { Brecha de color parduzco, algo gresosa, con } \\
\text { fragmentos de caliza }\end{array}$ & 40 & $\mathrm{X}$ & $\mathrm{X}$ & $\mathrm{X}$ & \\
\hline N. 3 & Nivel lenticular con concreciones calcáreas & 10 & & $\mathrm{X}$ & $\mathrm{X}$ & \\
\hline N. 4 & $\begin{array}{l}\text { Nivel arcillo-arenoso, ceniciento-parduzco, con } \\
\text { fragmentos de concreciones calcáreas }\end{array}$ & 30 & & $\mathrm{X}$ & $\mathrm{X}$ & $\mathrm{XX}$ \\
\hline N. 5 & Capa arcillo-limonosa & $2-3$ & & $\mathrm{X}$ & $\mathrm{X}$ & $\mathrm{X}$ \\
\hline N. 6 & $\begin{array}{l}\text { Brecha compacta con numerosos fragmentos y } \\
\text { concreciones calcáreas }\end{array}$ & $80-100$ & $\mathrm{X}$ & $\mathrm{XXX}$ & $\mathrm{X}$ & $\mathrm{XX}$ \\
\hline N. $6 \mathrm{a}$ & Nivel pardo-oscuro a negro, arenoso, concrecionado & $10-20$ & & $\mathrm{XX}$ & $\mathrm{X}$ & $\mathrm{XX}$ \\
\hline N. 7 & Nivel arenoso, pardo-grisáceo & 20 & & $\mathrm{X}$ & $\mathrm{XX}$ & $\mathrm{XXX}$ \\
\hline N. 8 & $\begin{array}{l}\text { Tierra pardo-oscura y negra, más o menos } \\
\text { consolidada, con restos de acumulación de cenizas }\end{array}$ & 30 & $\mathrm{XX}$ & $\mathrm{X}$ & $\mathrm{XX}$ & $\mathrm{XXX}$ \\
\hline N. 9 & Nivel estalagmítico espeso & $?$ & & $\mathrm{X}$ & $\mathrm{XXX}$ & $\mathrm{XX}$ \\
\hline N. 10 & $\begin{array}{l}\text { Arena arcillosa amarillenta, estéril, sobre el fondo de } \\
\text { la cavidad }\end{array}$ & ? & & & & \\
\hline
\end{tabular}

Tab. 1. Secuencia estratigráfica (según O. Veiga Ferreira y colaboradores, 1962): (1) carnívoros; (2) hervíboros. X, XX, $\mathrm{XXX}$ : grado de frecuencia. 


\begin{tabular}{|l|r|r|}
\hline \multicolumn{1}{|c|}{ Especie } & $N^{o}$ & $\%$ \\
\hline Crocuta crocuta spelaea & 24 & 9,3 \\
Felis sylvestris & 1 & 0,4 \\
Lynx pardina spalaea & 7 & 2,7 \\
Canis lupus & 2 & 0,8 \\
Ursus arctos & 1 & 0,4 \\
Dicerorhinus hemitoechus & 15 & 5,8 \\
Equus caballus ssp 1 y 2 & 16 & 6,2 \\
Cervus elaphus & 151 & 58,5 \\
Capreolus capreolus & 1 & 0,4 \\
Copra pyrenaica & 22 & 8,5 \\
Bos primigenius & 15 & 5,8 \\
\hline Total de restos identificados & 255 & \\
\hline \multicolumn{2}{|l|}{ Otras especies referidas: } \\
Vespertilio sp., Felis pardus, Vulpes vulpes, Mus sp., Oryctola- \\
gus cuniculus, Testudo sp., Helix nemoralis, etc. \\
\hline
\end{tabular}

Tab. 2. Asociaciones faunísticas. Niveles 6 a 8 (según inventario de J.L. Cardoso, 1993).

\section{INDUSTRIA LÍTICA}

\subsection{Aspectos generales}

Casi la totalidad de los cerca de seis millares de artefactos obtenidos en Gruta Nova de Columbeira provienen de las excavaciones realizadas en 1962. Las operaciones posteriores de limpieza de perfiles estratigráficos y sondeos apenas si permitieron detectar algunas decenas más (Tab. 3). Teniendo en cuenta estos datos y las dificultades que hay para articular las observaciones que han motivado las diferentes intervenciones, hemos optado por centrar nuestro estudio exclusivamente en la industria obtenida en las excavaciones de 1962, que posee elementos suficientes en posición estratigráfica (5368 artefactos líticos, que representan más del 90\% del total registrado en esa campaña).

En términos globales, la industria acredita una ocupación importante de la cavidad por parte de las poblaciones que la frecuentaron. Sin pretender realizar cálculo alguno en cuanto a la posible intensidad de ocupación (relacionando, por ejemplo, los artefactos líticos con la dimensión del espacio disponible, la potencia de los niveles de procedencia y la franja temporal a que corresponden, ejercicios que en buena medida consideramos artificiales), debemos en cualquier caso reconocer que la presencia de un total de casi seis millares de artefactos en un espacio relativamente pequeño (menos de $100 \mathrm{~m}^{2}$ de superficie útil), a lo largo de una potencia estratigráfica inferior a 2 metros, que podría corresponder a un lapso de pocos millares de años, sugiere que el local fue repetidamente visitado y/o ocupado de forma prolongada.

Estas observaciones resultan más evidentes si procedemos a un análisis más detallado. En efecto, podemos verificar que la absoluta mayoría de la industria, más de cuatro millares y medio de artefactos, se encontraba en las dos capas inferiores (n. 7 y 9), cuya potencia estratigráfica conjunta no llega a medio metro. Inversamente, las capas superiores con vestigios de ocupación humana (n. 4 a 6a), cuya potencia es tres veces superior, cerca de un metro y medio, contienen menos de un millar. La comparación directa entre los niveles 8 y 6 , los que mejor representan los respectivos bloques sedimentarios, es particularmente reveladora: casi dos millares y medio de artefactos de la capa 8 , con cerca de $30 \mathrm{~cm}$ de potencia, por menos de medio centenar en la 6 , que tenía casi un metro de espesor. En el mismo sentido abogan los resultados del análisis de las asociaciones faunísticas (Tab. 2), que muestran el predominio de carnívoros sobre herbívoros en el nivel 6, y una situación inversa en el 8. En fin, las acumulaciones de restos carbonosos, raros en el nivel 6 y abundantísimos en el 8 (Ferreira, 1984: 366), corroboran la misma impresión. Parece posible concluir con cierto grado de seguridad que existieron en esta gruta

\begin{tabular}{|c|c|c|c|c|c|c|c|c|c|c|c|c|c|c|c|c|c|c|}
\hline & \multicolumn{18}{|c|}{ NIVELES } \\
\hline & \multicolumn{2}{|c|}{4} & \multicolumn{2}{|c|}{5} & \multicolumn{2}{|c|}{6} & \multicolumn{2}{|c|}{$6 a$} & \multicolumn{2}{|c|}{7} & \multicolumn{2}{|c|}{8} & \multicolumn{2}{|c|}{9} & \multicolumn{2}{|c|}{ diversos } & \multicolumn{2}{|c|}{1971} \\
\hline & $n .^{o}$ & $\%$ & $n .^{o}$ & $\%$ & $n .{ }^{0}$ & $\%$ & $n .^{o}$ & $\%$ & $n .^{o}$ & $\%$ & $n .^{o}$ & $\%$ & $n .^{\circ}$ & $\%$ & $n .^{o}$ & $\%$ & $n .^{\circ}$ & $\%$ \\
\hline Esquirlas & 13 & 12,1 & 17 & 32,7 & 166 & 37,3 & 56 & 24,1 & 508 & 27 & 601 & 24,7 & 78 & 35,6 & 121 & 25,9 & 8 & 20,5 \\
\hline Lascas & 71 & 66,4 & 29 & 55,8 & 205 & 46,1 & 126 & 54,3 & 1.051 & 55,9 & 1.406 & 57,8 & 88 & 40,2 & 302 & 64,7 & 22 & 56,4 \\
\hline Utensilios (a) & 18 & 16,8 & 2 & 3,8 & 40 & 9,0 & 41 & 17,7 & 267 & 14,2 & 331 & 13,6 & 40 & 18,3 & 37 & 7,9 & 5 & 12,8 \\
\hline Núcleos & 5 & 4,7 & 3 & 5,8 & 30 & 6,7 & 9 & 3,9 & 43 & 2,3 & 88 & 3,6 & 10 & 4,6 & 7 & 1,5 & 4 & 10,3 \\
\hline Otros (b) & 0 & 0 & 1 & 1,9 & 4 & 0,9 & 0 & 0 & 11 & 0,6 & 7 & 0,3 & 3 & 1,4 & 0 & 0 & 0 & 0 \\
\hline Total & 107 & 100 & 52 & 100 & 445 & 100 & 232 & 100 & 1.880 & 100 & 2.433 & 100 & 219 & 100 & 467 & 100 & 39 & 100 \\
\hline
\end{tabular}

Tab. 3. Grandes categorías tecno-tipológicas (total de la industria). (a): según recuento esencial (sistema Bordes). (b): bloques probados, fragmentos inclasificables, "manuports", etc. 
momentos de ocupación humana intensa, quizá algunos horizontes pudieran corresponder a verdaderas residencias-base (n. 7 y 8), mientras que otros se habrían formado con ocasión de ocupaciones más o menos fugaces (n. 4 a 6a). Por lo menos en un caso (n. 6) responderían a cortos periodos de permanencia durante fases en las que la cueva era sobre todo ocupada por carnívoros, entre los cuales sobresale la hiena de las cavernas, denunciada tanto por la presencia de restos óseos como de coprolitos.

Estas ideas pueden ampliarse mediante el análisis pormenorizado de la industria lítica de cada nivel (Tab. 3), como exponemos a continuación comenzando por la base de la secuencia.

Nivel 9: horizonte estalagmítico espeso, constituido por niveles lenticulares o bolsadas, de potencia no determinada. En estas circunstancias puede comprenderse el escaso conjunto que aportó (219 artefactos). Al margen de las limitaciones que impone una muestra tan reducida, se verifica una extraordinaria representación de utensilios retocados $(18,3 \%)$, en un contexto en el que los núcleos se encuentran representados moderadamente, incluyendo formas apenas esbozadas, las esquirlas abundan y las lascas son relativamente escasas. De esta composición de la industria parece desprenderse la idea de que los primeros grupos humanos que frecuentaron esta cavidad realizaron una gestión muy económica de los soportes disponibles. Estos eran a veces introducidos en la cueva como lascas pre-conformadas, y sobre todo como masas nucleares en diversos estados de elaboración. A partir de estos soportes se habrían obtenido utensilios retocados, que a su vez fueron objeto de rejuvenecimientos sucesivos de los filos, dando lugar al alto número de esquirlas apuntado. Un panorama industrial semejante es consistente con la interpretación de estas primeras ocupaciones como frecuentaciones ocasionales de la cavidad, guiadas por patrones de eficacia económica, pero desvinculadas de un flujo regular de materias primas desde el exterior, ventajoso en la práctica cuando y sólo si el local funcionaba como base residencial más estable.

Nivel 8: extenso y con cerca de $30 \mathrm{~cm}$ de espesor, muy rico en restos carbonosos -estructuras de combustión según los primeros excavadores- encierra, como ya ha dicho, el principal nivel de ocupación del sitio. Su gran serie industrial (2433 artefactos) permite garantizar la validez estadística de los resultados obtenidos en orden a su diagnosis.
Al nivel que nos situamos, se registra una relativa escasez de núcleos y bloques brutos (manuports)o probados, asi como, inversamente, una significativa cantidad de utensilios. Las lascas corresponden a poco más de la mitad de la muestra, una representación importante, si bien inferior a la esperable, a juzgar por la cual hay que considerar que parte de las actividades de talla fueron realizadas en otro lugar. Las esquirlas, en porcentaje significativo, pero relativamente bajo, sugieren que dentro de la gruta se ejecutaron algunas acciones de talla para acabar utensilios y de retoque de los filos. La principal diferencia entre la industria de este nivel y la del subyacente, no atribuible únicamente a variaciones estadísticas aleatorias, se da en la representación de utensilios y esquirlas residuales. Su menor frecuencia en esta capa puede revelar el menor empeño en la conservación de los utensilios, traducido tanto por un uso breve y un abandono fortuito, más habitual fuera del área residencial, como por la menor insistencia en el rejuvenecimiento de los filos útiles. Estas diferencias cobran todo el sentido si tomamos en cuenta la probable fugacidad de la ocupación inicial (n. 9) y la obvia intensidad de la siguiente ocupación (n. 8), quizás encuadrable dentro de un concepto de campamento residencial de base, donde los comportamientos técnicos son más perdularios, por naturaleza.

Nivel 7: menor espesor y extensión superficial que el precedente. Tampoco se encontraron en él las acumulaciones de restos carbonosos observadas en el anterior. No obstante, puede considerarse que la industria lítica es idéntica a la del nivel 8. Incluso su expresión numérica (1880 artefactos) es proporcionalmente la misma, teniendo en cuenta las diferencias de espesor y superficie indicadas. Podemos partir por tanto de presupuestos interpretativos idénticos, aceptando que en ambos paquetes sedimentarios se producen las frecuentaciones humanas más intensas de la cueva, siendo los únicos momentos para los que es posible admitir la hipótesis de ocupaciones consistentes, de caracter residencial continuado.

Nivel 6a: en rigor, desde el punto de vista de la dinámica sedimentaria, constituye la base del nivel siguiente. Sin embargo, al haber sido individualizado en las primeras excavaciones, y dado que las respectivas industrias líticas ofrecen diferencias marcadas, hemos optado por mantenerlas aparte, al plantearse la posibilidad de que puedan corresponder a episodios ocupacionales diferenciados. En términos cuantitativos globales el conjunto líti-

T. P., 55, n. ${ }^{\circ} 1,1998$ 
co es manifiestamente escaso. Pese a tratarse de una capa delgada (de 10 a $20 \mathrm{~cm}$ ), este espesor sería suficiente para que, si hubiera soportado una ocupación humana importante, la industria fuera bastante más numerosa. Los 232 artefactos aquí recogidos parecen un testimonio efectivo de una ocupación discreta. Si consideramos también, por un lado la escasa representación de núcleos y la moderada presencia de lascas, y por otro la fuerte presencia de utensilios, optaríamos por aceptar un patrón algo semejante al considerado para el nivel 9 , donde una gran parte de los soportes utilizados, núcleos y lascas que serían transformados en utensilios, fueron introducidos en la gruta ya conformados. Los utensilios, empleados en buena medida de forma expeditiva, también habrían sido en ciertos casos sometidos a avivados de los filos, dando lugar a una producción de esquirlas que sin ser muy alta si se acusa claramente.

Nivel 6: como quedó indicado, constituye una de las unidades sedimentarias más importantes de la gruta. Muy extenso y espeso, casi un metro, aparecía brechificado en diversas áreas, especialmente cerca de la entrada primitiva. Constituye el palimpsesto sedimentario de mayores proporciones, una fase en que la cavidad era frecuentada por las fieras, y que pone en primer plano el problema de la errónea mezcla de episodios ocupacionales diferentes. Aparentemente estamos en el momento en que se introducen en la cueva mayores cantidades, siempre, claro, relativas, de masas nucleares, y en el que, correlativamente, se observaron menor número de lascas y utensilios, dando pié a suponer que parte fueron transportados al exterior. Tampoco, teniendo en cuenta las dificultades de la excavación, podemos excluir la hipótesis de que parte de los clastos de menor tamaño, como lascas y utensilios, no fueran recogidos, distorsionando el balance final. En cualquier caso, por el análisis que hemos efectuado de los cuadernos de campo y de las muestras de brecha que han sido conservadas, nos inclinamos a creer que en lo esencial el conjunto lítico recogido es representativo de esta unidad sedimentaria, y su escasez global (445 artefactos) corresponde a un patrón real, cuya interpretación ya sugerimos anteriormente. En el plano analítico ahora adoptado se comprueba la ocurrencia de un porcentaje significativo de esquirlas de talla, así como una representación considerable de núcleos, algunos de ellos en fases iniciales de su explotación, y la presencia si bien residual, de bloques probados y manuports. A tenor de estas frecuencias y del bajo porcentaje de utensilios y lascas simples, es posible concluir que en esta fase se verificaron en el interior de la cueva procesos de talla, documentándose en algunos casos la casi totalidad de las respectivas cadenas operatorias, y detectándose incluso indicios de transporte de subproductos -lascas y utensilios- al exterior. Por otro lado es posible afirmar que se procuró una considerable rentabilización de los utensilios por medio del rejuvenecimiento de sus filos.

Nivel 5: su industria es la más limitada de todo el yacimiento: 52 artefactos. Nos encontramos sin embargo ante un fino lecho limo-arcilloso, de 2-3 $\mathrm{cm}$, por lo que parece imposible interpretar desde un punto de vista histórico tan escasa representación. El reducido tamaño obliga a desistir de cualquier intento de diagnosis, por lo que prescindiremos de este nivel en el desarrollo analítico que efectuaremós, no incluyéndolo en gráficos y apenas en cuadros, únicamente a efectos del registro general de datos, aún a pesar de que en este caso den lugar frecuentemente a porcentajes e índices algo anómalos, a causa de los valores numéricos absolutos en que se asientan.

Nivel 4: su gran escasez de artefactos líticos no puede explicarse ni por pérdidas imputables a los métodos de excavación, pues se trata de sedimentos arcillo-arenosos sin compactar, fáciles de excavar, ni por la naturaleza del nivel, un horizonte extenso con cerca de $30 \mathrm{~cm}$ de potencia. Estamos pues ante factores que pueden conferir un significado histórico real a la baja intensidad de la ocupación humana en esta fase. La escasez de industria lítica afecta negativamente a las posibilidades de efectuar cualquier interpretación basada en apreciaciones estadísticas de sus componentes. En cualquier caso parece posible conceder valor a la ausencia de esquirlas de talla y de bloques en bruto o probados. Se observa una subrepresentación de núcleos, aunque todos ellos en avanzado estado de explotación. De manera inversa, los utensilios alcanzan un valor relativo muy elevado $(16,8 \%)$. En consecuencia, basándonos en la introducción en la gruta ya de utensilios elaborados en el exterior, ya de soportes nucleares completamente conformados, sugerimos para este nivel una ocupación humana discreta. Estaríamos ante un uso de la cueva semejante al de los niveles 6a y 9. Contrariamente a lo que en estos se observaba, especialmente en el nivel 9, el número importante de utensilios y la escasez de esquirlas apuntan que 
no se realizaría el reavivado sistemático de los filos, sino una fabricación sucesiva de los mismos, unida a una utilización inmediata.

Retomaremos más adelante los principales indicadores que se desprenden de la caracterización somera que acabamos de hacer, procurando en especial verificar en ellos la dinámica de la presencia humana en la cueva a lo largo de la secuencia sedimentaria. De momento pueden retenerse los siguientes aspectos de estas primeras observaciones:

- Para ningún momento de la ocupación de la cavidad se ha documentado que en su interior se realizara la totalidad, o siquiera la mayor parte, de las actividades de talla de la piedra. Por el contrario, los soportes fueron casi siempre introducidos ya pre-conformados: principalmente lascas, pero también núcleos en estado de configuración volumétrica adelantada. Algunas fluctuaciones menores llegaron a ser detectadas en este dominio. Destaca al respecto el nivel 6, que ofrece el ejemplo de mayor acarreo de masas nucleares a la cueva y de actividad de talla dentro de la misma.

- Los índices de transformación de los soportes potenciales en utensilios son siempre considerables, excepto en el grupo de talla Levallois, y de ahí el "caracter levalloisiense" al que nos referiremos más adelante. Lo porcentaje de utensilios se sitúa sistemáticamente por encima del $10 \%$ de la totalidad de cada conjunto lítico, con la excepción de nuevo del nivel 6, en el que se queda en el $9 \%$. En algunos casos estos valores son bastante más elevados, entre $15 \%$ y $18 \%$. Es cierto que en las cuevas el porcentaje de útiles retocados es habitualmente superior al de los sitios al aire libre, más próximos a las fuentes de materias primas, pero no por eso dejan de ser menos destacables los valores aquí registrados. Incluso si admitimos algún sesgo inflacionista derivado de alguna selección durante las excavaciones que, de haber existido, se nos figuran irrelevantes, una vez que los conjuntos reunidos no sugieren ningún tipo de selección intencional y el haberse cribado sistemáticamente los sedimentos en la excavación de 1962 constituye una garantía suficiente de su representatividad.

- Existen niveles en que diversos factores (naturaleza de la sedimentación, asociaciones faunísticas, restos carbonosos e industrias líticas, en la doble perspectiva en este caso de sus expresiones numéricas globales y de su estructura a nivel de las grandes categorías tecno-tipológicas establecidas) sugieren frecuentaciones de fugacidad mar- cada (n. 9, 6a, 4). En todos ellos se registran índices especialmente elevados de aprovechamiento de los soportes, traducidos en utensilios. Sin embargo algunas diferencias se dan en cuanto a los caminos por los que se alcanza tal eficacia, bien mediante el recurso a la fabicación de nuevos utensilios, destinados a tener vida corta y uso rápido (n. 4), bien a través del rejuvenecimiento más frecuente de los filos activos de utensilios ya existentes, conservándolos más tiempo (n. 9).

- De manera inversa, existen dos niveles (8 y 7) que, al aplicar los mismos criterios, atestiguan la ocurrencia de verdaderos horizontes de ocupación regular de la cavidad, asimilándose incluso al modelo teórico de residencia-base. Presentan industrias líticas numerosas y bastante semejantes en su composición tecno-tipológica elemental. Una parte importante de las acciones de talla, en especial las relativas al inicio de las secuencias operatorias, fueron practicadas en el exterior, mientras que al interior las lascas se trasladaron bajo forma de soportes pre-conformados y de núcleos en fases de configuración volumétrica avanzada; excepcionalmente se introdujeron bloques sólo probados. Se registra un uso predominantemente expeditivo de los utensilios, con grados de rejuvenecimento de filos útiles relativamente bajos.

\subsection{Gestión de las materias primas}

Las consideraciones hasta aquí efectuadas, con base en la expresión cuantitativa global de los conjuntos líticos de cada nivel y en su descomposición en grandes categorías tecno-tipológicas, si por un lado permite obtener una primera lectura acerca de la naturaleza de las presencias humanas detectadas, se revela por otro lado manifiestamente incapaz de atribuirlas cualquier cronología. A partir de los datos que hasta aquí hemos manejado, se podrían desarrollar argumentos idénticos a propósito de una industria lítica de cualquier época. Parece importante conducir ahora nuestro análisis en el sentido mejor para caracterizar cronológico-culturalmente los conjuntos líticos en estudio.

Una primera plataforma de observación es la de las opciones en cuanto a selección y eventual utilización diferencial de las materias primas obtenidas (Tab. 4 y Fig. 2). Se torna evidente que no existen, en nigún momento de la ocupación, estrategias basadas en la adquisición intensiva de una

T. P., 55, n. ${ }^{\circ} 1,1998$ 


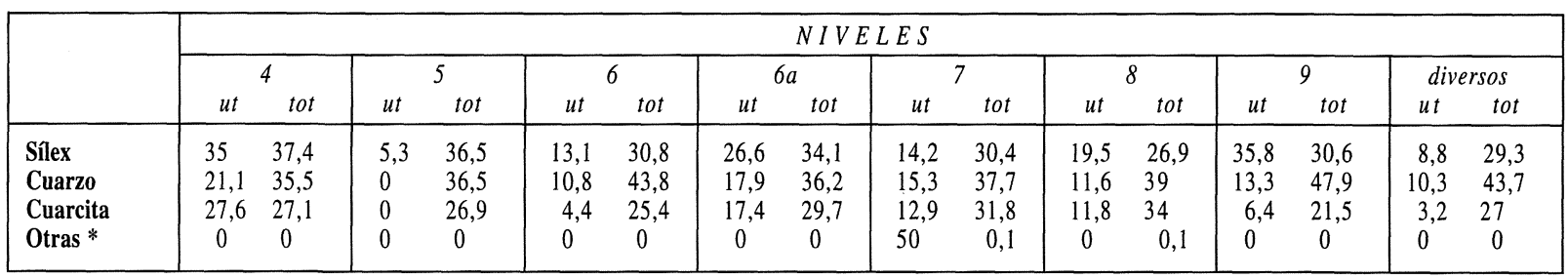

* Rocas ígneas, liditos, grauvacas, etc.

Tab. 4. Materias primas. ut: utensilios; tot: total de la industria (porcentajes, por niveles; utensilios: porcentaje en relación al total dentro de cada materia prima).

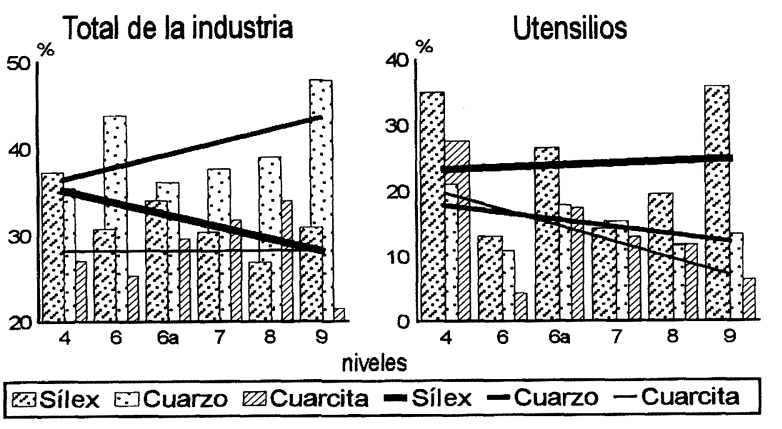

Fig. 2. Materias primas.

sóla roca. Sílex, cuarzo y cuarcita constituyen los grupos dominantes, distribuidos de manera casi equilibrada. Puede verificarse una marcada diversidad de materias primas, de la que cuadros y gráficos sólo dan cuenta de manera parcial, ya que, por comodidad de representación, reúnen en una misma categoría petrográfica ejemplares bastante diversos. Sólo en el grupo sílex, por ejemplo, pueden contabilizarse cerca de una decena de variedades -de colores vivos, patinado de blanco o crema, rosa, castaño oscuro, con foraminíferos, veteado, brechiforme, calcedonia, etc. Además se constata (Fig. 2) una tendencia evolutiva que matiza esta cuestión: se da un progresivo aumento de sílex a lo largo de la secuencia y una disminución correlativa del cuarzo, mientras que la cuarcita se mantiene estable. Es así posible concluir que los sucesivos usuarios de la cueva dan cuenta de una evolución en la que una creciente adquisición de sílex, y menor utilización del cuarzo, se inscriben dentro de un comportamiento tecnológico globalmente estable, asentado en un notorio oportunismo en el aprovisionamiento de recursos líticos.

Se podría admitir que las características indicadas, tanto en cuanto a su componente estructural invariante, como en su evolución temporal, pudieran obedecer sólamente a aspectos relacionados con la mayor o menor accesibilidad a las fuentes de materia prima. $\mathrm{Al}$ respecto debe tenerse en cuenta que los soportes utilizados revelan, mediante la observación de las superficies corticales conservadas, un mismo patrón de captación a lo largo de toda la secuencia: el sílex aparece fundamentalmente bajo forma de nódulos y cantos mal rodados, recogidos en el macizo calcáreo circundante y en la respectiva red hidrográfica secundaria; el cuarzo y la cuarcita llegan como cantos bien rodados-los de cuarzo menores por término medio que los de cuarcita-, muy abundantes en las tierras bajas que se extienden frente a la gruta. Es decir, no existirían dificultades de obtención para alguna de estas materias primas mayores que para otra, y nada revela que a lo largo de la frecuentación humana de la gruta hubiese habido alteraciones en este dominio. Es posible por tanto concluir que tanto la no utilización sistemática de una sóla roca, como el ligero aumento del recurso al sílex a lo largo del tiempo, corresponden a opciones tecno-culturales efectivas, y no sólamente al mero juego de factores medioambientales condicionantes.

Importaría aún verificar en que medida los comportamientos señalados tienen reflejo en aquello que a fin de cuentas constituye la razón de ser última de los procedimientos tecnológicos adoptados: la transformación de los soportes disponibles en utensilios. Sería tentador admitir que a la creciente adquisición de sílex correspondiese idéntico aumento de los índices de transformación en utensilios. Si un escenario tal se verificase y, adelantando un poco nuestro análisis, fuese igualmente acompañado por la introducción de nuevas tecnologías de talla y nuevos tipos de utensilios, se abriría la posibilidad de reclamar la existencia en este local de una evolución cultural más amplia, acaso testimonios de un paso, autónomo o por aculturación, a las industrias de tipo Paleolítico Superior. Pero nada de esto ocurre. A lo largo de la secuencia (Fig. 2 ), no existe ningún aumento, más bien una disminución de la proporción de soportes de sílex transformados en utensilios finales. A la inversa, au- 
menta considerablemente el grado de eficacia en el aprovechamiento del cuarzo, y sobre todo el de la cuarcita. En otras palabras, el mayor acopio de sílex no perjudica, antes estimula, el uso y rentabilización de las restantes materias primas. Veremos más adelante que los procedimientos técnicos adoptados y la panoplia de utensilios disponibles se mantienen sensiblemente constantes en todos los niveles. Por lo tanto, la interpretación que mejor se ajusta a los rasgos enunciados no es la de una creciente aproximación a los patrones de tipo Paleolítico Superior, sino, por el contrario, la de un refuerzo señalado de los parámetros propios del Paleolítico Medio.

\subsection{Características técnicas}

\subsubsection{Núcleos (Fig. 3)}

Como se ha dicho, la frecuencia de núcleos en cada nivel se encuentra siempre en cifras relativa- mente bajas, normales en cualquier caso para industrias en cueva. Documentando la existencia en el interior de una actividad en pos de conseguir soportes para utensilios, ellos patentizan igualmente la realización de actividades de talla en el exterior. Se podrá ahora profundizar en estas observaciones al descomponer este grupo de artefactos en algunas categorías elementales (Tab. 5): esbozos (tipo 0 ), núcleos de levantamientos dispersos no organizados (tipo 1), núcleos globulares (tipo 2), núcleos discoides (tipo 3), núcleos Levallois (tipo 4), núcleos de tipo Paleolítico Superior (tipo 5), fragmentos y restos inclasificables (tipo 6). La escasa representación de esbozos, así como de bloque brutos o probados (cf. Tab. 3), hace patente que gran parte de las operaciones de conformación inicial de los bloques seleccionados fue ejecutada en el exterior de la cueva. La importante representación de fragmentos y restos revela el importante grado de explotación al que fueron sometidos las masas nucleares, convertidas a veces

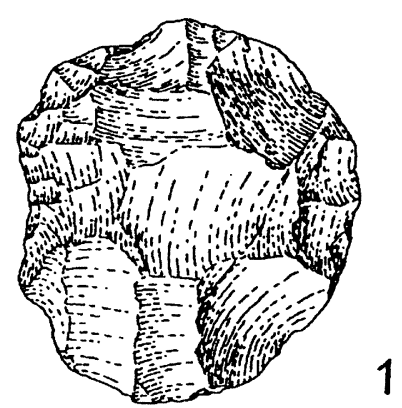

1

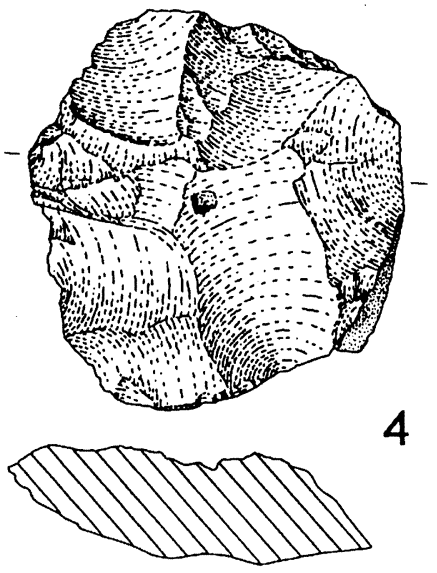

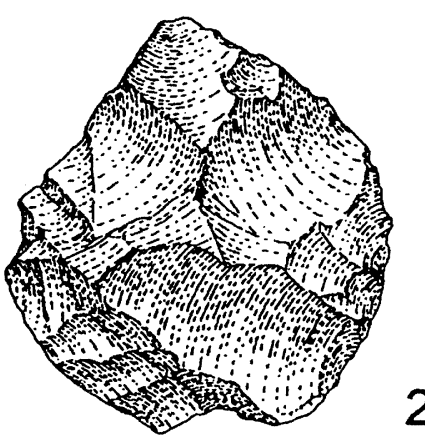

2

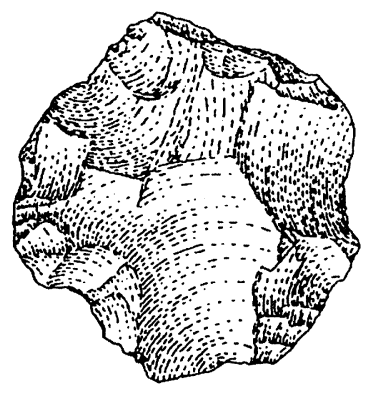

5
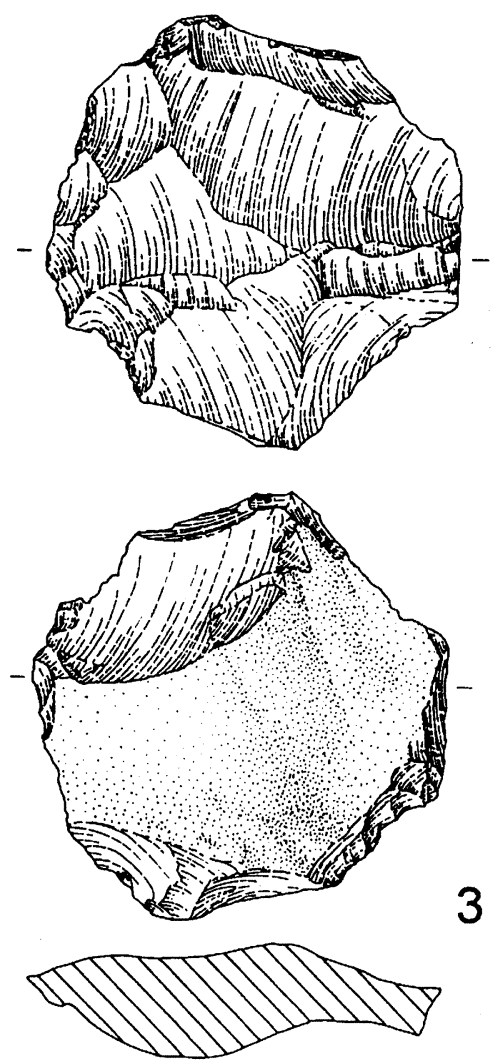

Fig. 3. Núcleos (todos del nivel 7): 1 a 4: discoides; 5: Levallois (1,2, 4: cuarcita; 4: sílex; 5: cuarzo)

T. P., 55, n. $^{\circ} 1,1998$ 


\begin{tabular}{|c|c|c|c|c|c|c|c|c|c|c|c|c|c|c|c|c|}
\hline & \multicolumn{16}{|c|}{$N I V E L E S$} \\
\hline & \multicolumn{2}{|c|}{4} & \multicolumn{2}{|c|}{5} & \multicolumn{2}{|c|}{6} & \multicolumn{2}{|c|}{$6 a$} & \multicolumn{2}{|c|}{7} & \multicolumn{2}{|c|}{8} & \multicolumn{2}{|c|}{9} & \multicolumn{2}{|c|}{ diversos } \\
\hline & $n .^{o}$ & $\%$ & $n .^{\circ}$ & $\%$ & $n .^{o}$ & $\%$ & $n .^{o}$ & $\%$ & $n .^{o}$ & $\%$ & $n^{o}$ & $\%$ & $n .^{\circ}$ & $\%$ & $n .^{\circ}$ & $\%$ \\
\hline Tipo 0 & 0 & 0 & 1 & 25 & 3 & 9,1 & 0 & 0 & 5 & 10,4 & 3 & 3,3 & 3 & 23,1 & 0 & 0 \\
\hline Tipo 1 & 0 & 0 & 0 & 0 & 3 & 9,1 & 1 & 11,1 & 0 & 0 & 3 & 3,3 & 0 & 0 & 0 & 0 \\
\hline Tipo 2 & 0 & 0 & 0 & 0 & 7 & 21,2 & 3 & 33,3 & 5 & 10,4 & 15 & 16,5 & 3 & 23,1 & 3 & 42,9 \\
\hline Tipo 3 & 1 & 20 & 0 & 0 & 8 & 24,2 & 2 & 22,2 & 9 & 18,8 & 26 & 28,6 & 3 & 23,1 & 1 & 14,3 \\
\hline Tipo 4 & 3 & 60 & 1 & 25 & 4 & 12,1 & 3 & 33,3 & 5 & 10,4 & 14 & 15,4 & 1 & 7,7 & 2 & 28,6 \\
\hline Tipo 5 & 0 & 0 & 0 & 0 & 0 & 0 & 0 & 0 & 0 & 0 & 4 & 4,4 & 0 & 0 & 0 & 0 \\
\hline Tipo 6 & 1 & 20 & 2 & 50 & 8 & 24,2 & 0 & 0 & 24 & 50 & 26 & 28,6 & 3 & 23,1 & 1 & 14,3 \\
\hline
\end{tabular}

Tab. 5. Núcleos.

en residuos inclasificables, idea confirmada por el acentuado grado de exhaustividad de la mayor parte de los núcleos.

En cuanto a la clasificación tipológica, en un plano global, se comprueba que los conjuntos de todos los niveles poseen una estructura básica relativamente estable. El grupo de núcleos con tendencia a quedar reducidos a dos caras opuestas (tipos 3 y 4) domina siempre sobre los núcleos menos organizados (tipos 1 y 2), mientras que los núcleos de concepción volumétrica tridimensional son prácticamente inexistentes (tipo 5). Nos encontramos claramente ante una configuración propia de una industria del Paleolítico Medio, carácter que se acentúa en su evolución diacrónica (Fig. 4): en conjunto, disminución relativa de los tipos 1 y 2 -muy comunes en industrias de tradición achelense- y aumentos de los tipos 3 y 4 ; en detalle, disminución acentuada de los tipos más simples, estabilidad de los núcleos discoides y aumento significativo de los núcleos Levallois. Es cierto que debe ser salvada la escasa representatividad numérica de los conjuntos líticos de los ni-

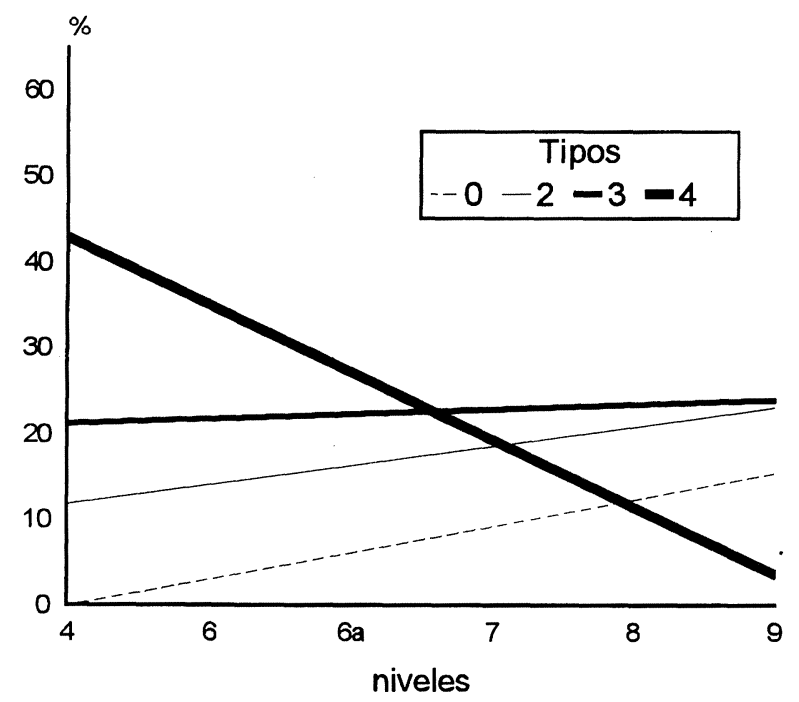

Fig. 4. Núcleos. Tendencias evolutivas. veles que contribuyen más a dibujar esta tendencia hacia el aumento notable de los núcleos Levallois (60\% en la capa 4, pero para un total de 9 ejemplares). Podría quizás considerarse que la sugerencia de un desarrollo tan importante de los núcleos Levallois, que superarían ampliamente en número a los discoides (Fig. 4) es excesiva. Pero este dato no altera ni contradice la idea de fondo que formulábamos: los núcleos de los conjuntos líticos de los diferentes niveles de esta cueva atestiguan un contexto técnico típicamente atribuible al Paleolítico Medio, cuyos caracteres diagnósticos no se diluyen, sino que más bien se refuerzan a través de la secuencia sedimentaria

\subsubsection{Talla (2) (Fig. 5)}

Una vez vistos los núcleos, vamos a examinar los principales aspectos técnicos detectados en el conjunto de los productos de talla, adoptando para ello alguno de los indicadores considerados en el ámbito del llamado "método Bordes" (Tab. 6 y Fig. 6). En lo que se refiere al índice Levallois técnico (IL), es obvio que de arriba a abajo de la secuencia estamos ante industrias Levallois, aunque los índices no sean altos. Sólo en el nivel 7 se sitúa cerca del límite inferior convencional, ya que los valores encontrados para el nivel 5 carecen, como ya subrayamos, de la necesaria consistencia estadística. En relación con los índices de facetado de los talones (IF y IFs), se observan cifras aparentemente muy bajas para una industria del Paleolítico Medio en cueva. En todo caso debe subrayarse que esos mismos índices alcanzan valores normales dentro de la talla Levallois. Una valoración más precisa de estas referencias debería tener en cuenta las características comunes observadas en las industrias del Paleolítico Medio portugués, con fre-

(2) Utilizamos este termino en sentido ámplio; excluimos del mismo las "esquirlas" (restos de talla con $<30 \mathrm{~mm}$ ) e incluimos la totalidad de los artefactos comprendidos en los términos "lascas" y utensilios de la tabla 3 . 

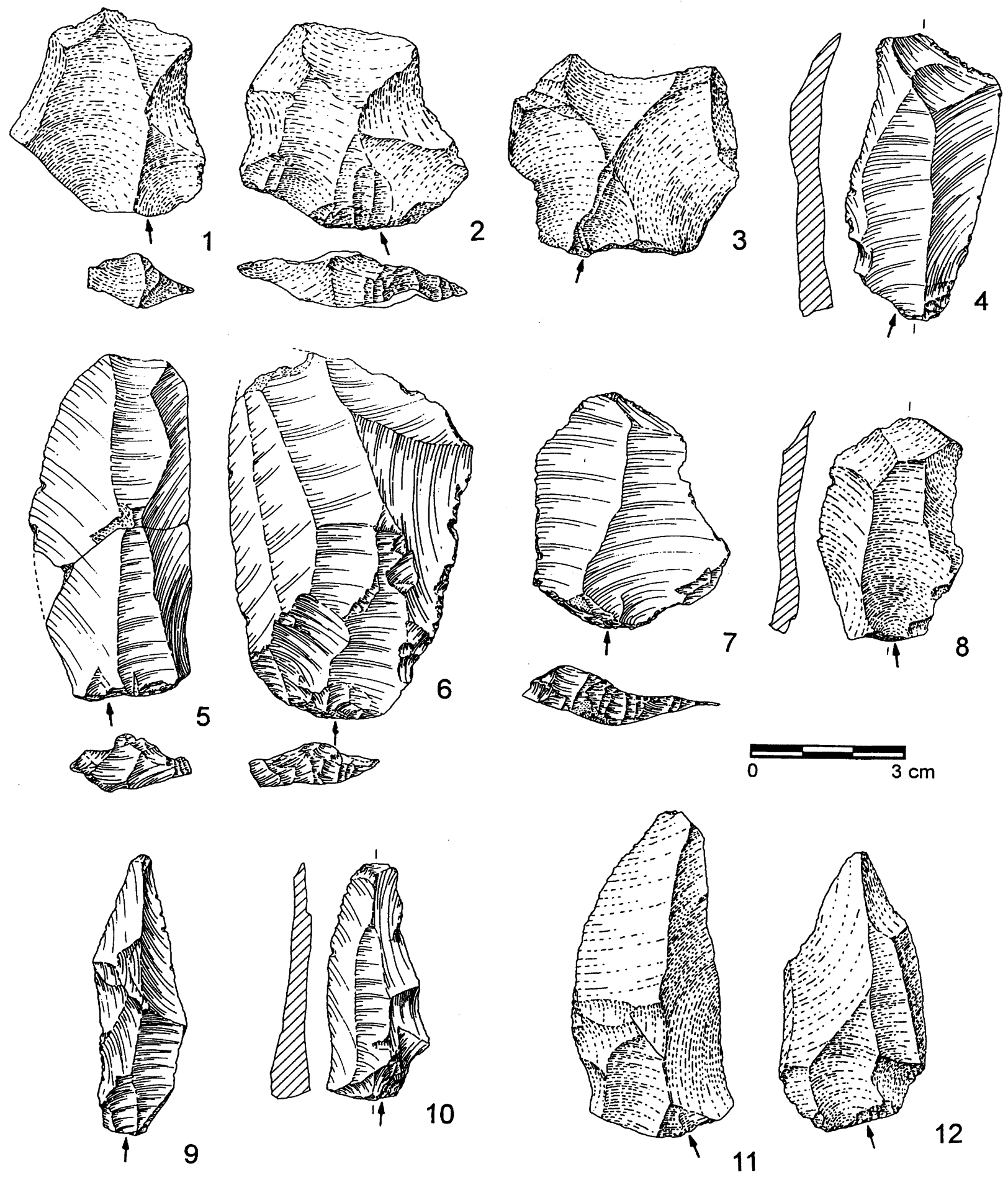

Fig. 5. Talla Levallois (1, 3, 4, 7, 10-12: nivel 7; 2, 5, 6: nivel 6a; 9: nivel 8). 1-8: lascas Levallois; 9-10: láminas Levallois; 11-12: puntas seudo-Levallois (1-3, 8, 12-13: cuarcita; 4-7, 9-10: sílex) 


\begin{tabular}{|l|c|c|c|c|c|c|c|}
\hline & \multicolumn{7}{|c|}{ NIVELES } \\
\cline { 2 - 8 } & 4 & 5 & 6 & $6 a$ & 7 & 8 & 9 \\
\hline IL & 28,2 & 13,8 & 20,2 & 22,6 & 17,1 & 20,9 & 29 \\
IF & 29,1 & 26,1 & 35 & 39,8 & 31,9 & 37,2 & 28,1 \\
IF * & 31,3 & 100 & 72,1 & 68,6 & 66,3 & 64,3 & 41,4 \\
IFs & 16,4 & 4,3 & 21 & 26 & 20,1 & 22 & 16,9 \\
IFs * & 31,3 & 25 & 46,5 & 54,3 & 45,9 & 45,5 & 24,1 \\
ILam & 5,7 & 0 & 1,8 & 3,4 & 2,9 & 2,9 & 5,9 \\
ILam * & 15,8 & 0 & 4,5 & 10,3 & 6,3 & 5,6 & 12,5 \\
\hline
\end{tabular}

(* índices en talla Levallois exclusivamente)

Tab. 6. Principales índices técnicos (según método Bordes). (*): índices en talla Levallois exclusivamente. IL: índice Levallois técnico. IF: índice de facetado amplio. IFs: índice de facetado restringido. ILam: índice laminar.

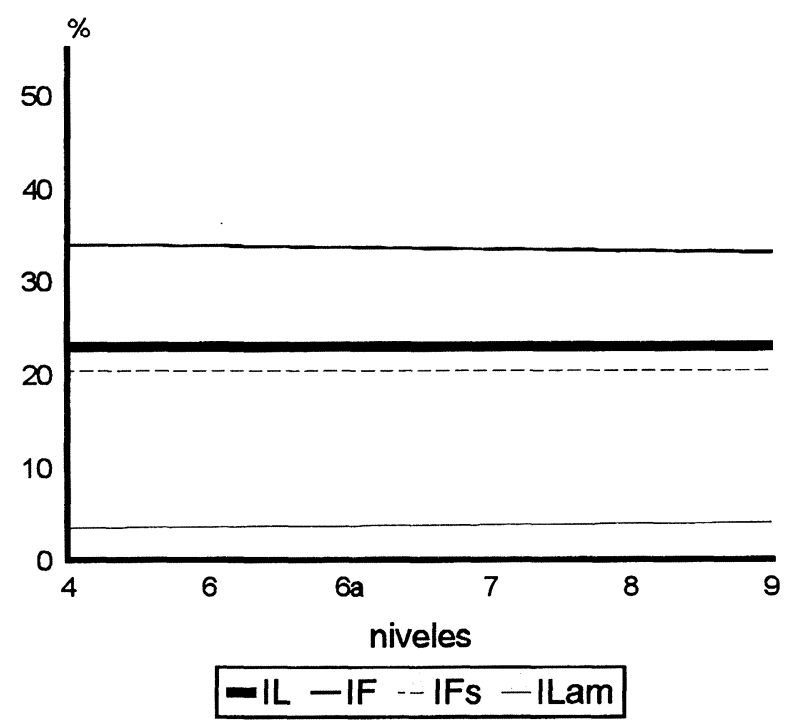

Fig. 6. Tendencias evolutivas de los principales índices técnicos. IL: índice Levallois técnico. IF: índice de facetado amplio. IFs: índice de facetado restringido. ILam: índice laminar.

cuencia sobre cantos rodados y con índices de facetado bajísimos. De momento queda sugerida la existencia en esta localidad de cadenas operativas diversas, o de diferentes estadios dentro de una misma cadena operativa, de tal modo que en las fases iniciales de la talla de los nódulos disponibles predominan las lascas de talones corticales y lisos, mientras que en las fases más avanzadas, concretamente en la extracción de soportes preconformados, son comunes los talones facetados.

En cuanto a la representación de soportes laminares (ILam), siempre muy baja, casi residual, verificamos la existencia de valores algo mayores en el grupo Levallois, especialmente en los nive- les $6 a$ y 4 , este último con un índice de 15,8 , casi en el límite inferior de lo que podría ser clasificado como una industria de tendencia laminar. Si se acepta el dato, representaría el primer -y único, como veremos- indicio de una cierta aproximación a modelos tecno-tipológicos tradicionalmente asimilados a las industrias de tipo Paleolítico Superior. Consideramos no obstante que una conclusión de tanto alcance no está justificada, tanto por su falta de correspondencia con todos los demás indicadores compulsables, como porque el tamaño del conjunto lítico en que se basa -89 elementos de talla- no permite demasiada confianza estadística en los resultados obtenidos.

La confirmación de que el carácter que acabamos de discutir carece de especial significado, queda patente en las tendencias evolutivas que presentan los índices antes citados (Fig. 6), cuya estabilidad es notoria. Los grupos que frecuentaron esta gruta mantuvieron casi invariable una misma tradición técnica a lo largo de toda la secuencia sedimentaria en que se documenta su presencia. Todos estos índices se resuelven gráficamente en líneas prácticamente horizontales

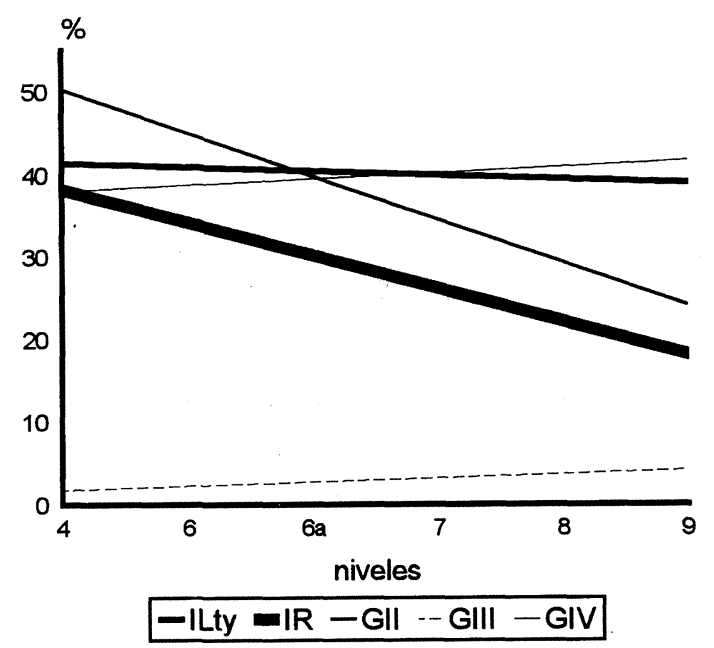

Fig. 7. Tendencias evolutivas de los principales índices tipológicos. ILty: índice Levallois tipológico. IR: índice de raederas. Grupo II: grupo musteriense. Grupo III: Paleolítico Superior. Grupo IV: grupo de denticulados.

\subsection{Características tipológicas}

No cabe en el ámbito de este texto desarrollar un estudio descriptivo completo, ni siquiera parcial, de los utillajes detectados. Esta información se recogerá en la monografía sobre el yacimiento 
actualmente en preparación. Nos limitaremos en estas circunstancias a presentar de manera resumida las principales características de los conjuntos de utensilios de cada capa, con objeto de realizar una diagnosis cultural para el conjunto mediante los índices y proporciones establecidos en el llamado "método Bordes".

En lo que se refiere a los rasgos elementales que definen los utillajes de cada nivel (Tab. 7 y 8), se puede indicar lo siguiente:

Nivel 9: incluye un total de 40 utensilios en cuenta esencial (ó 39, si aceptamos las pertinentes opiniones de algunos autores en cuanto a la conveniencia de excluir en este recuento los números 5 y 38 de la lista-tipo, que manifiestamente corresponden a un concepto de "utensilio a priori" que encaja mal aquí). Vimos ya que este conjunto alcanza un valor porcentual muy elevado en el conjunto lítico de este nivel (18,3\%, o 17,8\% si aplicamos la restricción apuntada), lo que en todo caso no exime de tener que considerar con reserva la validez estadística de los índices calculados, dado lo reducido de la muestra. Los denticulados y escotaduras constituyen el bloque principal de utensilios. Este grupo tipológico alcanza la cifra más alta de toda la secuencia (Grupo IV: 45,9). Por contra, las raederas presentan valores bastante bajos (IR: 12,5). Destaca el predominio de raederas "de tipo arcaico", esto es, comunes en las industrias achelenses (raederas transversales, sobre cara plana, con retoque abrupto, bifacial, alterno, etc.), sobre las raederas "de tipo evolucionado", esto es, comunes en las industrias musterienses (raederas simples, dobles, convergentes, etc.). En el plano de los productos Levallois, proporcionalmente poco transformados en utensilios (ILty:
40), se registra la importancia relativa de las formas poco elaboradas (ejes de lascado desviados, contornos irregulares, presencia de restos corticales importantes, etc.), las llamadas “atípicas", cerca del $40 \%$ de la suma atípicas+típicas.

Nivel 8: Comprende un total de 331 utensilios en cuenta esencial (ó 304 en los términos restrictivos antes expresados), un conjunto, por tanto, con buena representividad estadística. Los denticulados continúan siendo dominantes, llegando hasta una cifra casi idéntica a la de la capa subyacente (Grupo IV: 43,2), valor que además se eleva sensiblemente si se incluyen las escotaduras (Grupo IVa: 60,7). No obstante, se registra también algún crecimiento relativo de las raederas, aunque en cualquier caso situadas en valores relativamente bajos (IR: 21,5) y dominadas por los mismos "tipos arcaicos" antes referidos. El carácter poco elaborado resulta reforzado por la existencia de cuchillos de dorso, piezas con retoque somero de los filos y algunos cantos tallados. Las puntas cobran cierta representatividad (puntas Levallois + Levallois retocadas: 3,6\%, en cuenta esencial), sobre todo si incluimos las puntas seudo-levallois (10,3 $\%)$, las cuales están, como se sabe, muy ligadas a la explotación de núcleos discodes, dominantes en este nivel. Finalmente, por lo que se refiere a la ta1la Levallois, con un índice tipológico igualmente elevado (ILty: 42,3), observamos alguna disminución relativa de los soportes "atípicos" (cerca del $30 \%$ de la suma atípicos + típicos).

Nivel 7: igualmente ofrece una buena representatividad estadística, con un total de 267 utensilios en cuenta esencial (ó 235, en los términos restrictivos indicados). Los denticulados continúan siendo el grupo mayoritario, aunque en menor por-

\begin{tabular}{|c|c|c|c|c|c|c|c|c|c|c|c|c|c|c|c|c|}
\hline & \multicolumn{16}{|c|}{$N I V E L E S$} \\
\hline & \multicolumn{2}{|c|}{4} & \multicolumn{2}{|c|}{5} & \multicolumn{2}{|c|}{6} & \multicolumn{2}{|c|}{$6 a$} & \multicolumn{2}{|c|}{7} & \multicolumn{2}{|c|}{8} & \multicolumn{2}{|c|}{9} & \multicolumn{2}{|c|}{ diversos } \\
\hline & real & es. & real & es. & real & es. & real & es. & real & es. & real & es. & real & es. & real & es. \\
\hline ILty & 40,6 & 0 & 50 & 0 & 48,2 & 2.5 & 33.3 & 0 & 36,5 & 1,5 & 42,3 & 0,6 & 40 & 0 & 40 & 0 \\
\hline IR & 18,8 & 33,3 & 0 & 0 & 15,3 & 32,5 & 21,7 & 36,6 & 19,5 & 32,6 & 11,3 & 21,5 & 8,2 & 12,5 & 23,1 & 40,5 \\
\hline IAu & 0 & 0 & 0 & 0 & 0 & 0 & 0 & 0 & 0 & 0 & 0,6 & 1,2 & 0 & 0 & 0 & 0 \\
\hline IB & 0 & 0 & & 0 & 0 & 0 & 0 & 0 & 0 & 0 & 0 & 0 & 0 & 0 & 0 & 0 \\
\hline IQ & 0 & 0 & 0 & 0 & 0 & 0 & 0 & 0 & 0 & 0 & 0 & 0 & 0 & 0 & 0 & 0 \\
\hline Grupo I & 40,6 & 0 & 50 & 0 & 48,2 & 2,5 & 33,3 & 0 & 36,5 & 1,5 & 42,3 & 0,6 & 40 & 0 & 40 & 0 \\
\hline Grupo II & 28,1 & 50,0 & 25 & 50 & 17,6 & 37,5 & 26,1 & 43,9 & 25,7 & 43,1 & 16,3 & 30,8 & 11,5 & 17,5 & 23,1 & 40,5 \\
\hline Grupo III & 0 & 0 & 0 & 0 & 0 & 0 & 5,8 & 9,8 & 0,9 & 1,5 & 2,1 & 3,9 & 0,2 & 2,7 & 1,5 & 2,7 \\
\hline Grupo IV & 25 & 44,4 & 25 & 50 & 17,6 & 37,5 & 20,3 & 34,1 & 20,4 & 34,1 & 22,8 & 43,2 & 26,2 & 45,9 & 26,2 & 45,9 \\
\hline Grupo IV (a) & 25 & 44,4 & 25 & 50 & 27,1 & 57,5 & 23,2 & 39 & 26,6 & 44,6 & 32,1 & 60,7 & 30,8 & 54,1 & 30,8 & 54,1 \\
\hline
\end{tabular}

Tab. 7. Principales índices tipológicos (según método Bordes). ILty: índice Levallois tipológico. IR: índice de raederas. IAu: índice achelense unifacial (índice de cuchillos de dorso). IB: índice de bifaces. IQ: índice de raederas tipo Quina. Grupo I: grupo Levallois. Grupo II: grupo musteriense. Grupo III: Paleolítico Superior. Grupo IV: grupo de denticulados. Grupo IV (a): grupo de denticulados y escotaduras. 


\begin{tabular}{|c|c|c|c|c|c|c|c|c|c|c|c|c|c|c|c|c|}
\hline & \multicolumn{16}{|c|}{ NIVELES } \\
\hline & (l) & (2) & 5 & (2) & (1) & (2) & $6 a$ & (2) & (1) & 7 (2) & (l) & (2) & (I) & (2) & & $\begin{array}{l}\text { sos } \\
\text { (2) }\end{array}$ \\
\hline 1 & 9 & 9 & 1 & 1 & 25 & 25 & 16 & 16 & 71 & 71 & 177 & 177 & 11 & 11 & 9 & 9 \\
\hline 2 & 3 & 3 & 1 & 1 & 13 & 13 & 6 & 6 & 78 & 78 & 76 & 76 & 7 & 7 & 15 & 15 \\
\hline $\mathbf{3}$ & 1 & 1 & & 0 & 2 & 2 & 1 & 1 & 10 & 10 & 10 & 10 & 1 & 1 & 2 & 2 \\
\hline 4 & & 0 & & 0 & 1 & 1 & & 0 & 4 & 4 & 2 & 2 & 1 & 1 & & 0 \\
\hline 5 & & 1 & & 1 & & 2 & & 1 & & 22 & & 22 & & 1 & & 0 \\
\hline 6 & & 0 & & 0 & & 0 & & 0 & 2 & 2 & & 1 & & 0 & & 0 \\
\hline 7 & & 0 & & 0 & & 0 & & 2 & & 4 & & 7 & & 0 & & 0 \\
\hline 8 & 2 & 2 & & 0 & & 0 & & 0 & & 0 & 1 & 1 & & 1 & & 0 \\
\hline 9 & & 0 & & 0 & & 1 & & 0 & 3 & 11 & 1 & 9 & & 0 & & 0 \\
\hline 10 & 4 & 4 & & 0 & 2 & 5 & 1 & 5 & 2 & 18 & 5 & 15 & 1 & 1 & 1 & 6 \\
\hline 11 & 1 & 1 & & 0 & & 2 & 1 & 3 & & 16 & 1 & 8 & & 1 & & 1 \\
\hline 12 & & 0 & & 0 & & 0 & & 0 & & 1 & & 1 & & 0 & & 0 \\
\hline 13 & & 0 & & 0 & & 0 & & 0 & 2 & 4 & & 0 & & 0 & & 0 \\
\hline 14 & & 0 & & 0 & & 0 & & 0 & & 0 & & 0 & & 0 & & 0 \\
\hline 15 & & 0 & & 0 & & 1 & & 0 & 1 & 2 & & 1 & & 0 & & 0 \\
\hline 16 & & 0 & & 0 & & 0 & & 0 & & 0 & 1 & 1 & & 0 & & 1 \\
\hline 17 & & 0 & & 0 & & 1 & & 1 & & 0 & & 1 & & 0 & & 0 \\
\hline 18 & & 0 & & 0 & & 0 & & 0 & & 1 & & 0 & & 0 & & 0 \\
\hline 19 & & 0 & & 0 & & 0 & & 1 & 2 & 7 & & 2 & & 0 & & 0 \\
\hline 20 & & 0 & & 0 & & 0 & & 0 & & 0 & & 0 & & 0 & & 0 \\
\hline 21 & & 1 & & 0 & 1 & 0 & 1 & 1 & & 3 & & 2 & & 2 & & 0 \\
\hline 22 & & 0 & & 0 & & 0 & & 0 & & 1 & 2 & 4 & 1 & 0 & & 1 \\
\hline 23 & & 0 & & 0 & & 0 & & 0 & 1 & 6 & 1 & 6 & & 0 & & 0 \\
\hline 24 & & 0 & & 0 & 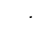 & 1 & & 1 & 1 & 1 & 1 & 4 & & 0 & & 0 \\
\hline 25 & & 0 & & 0 & & $i$ & & 2 & & 4 & 2 & 9 & & 0 & & 2 \\
\hline 26 & & 0 & & 0 & & 1 & & $i$ & & 9 & & 4 & 1 & 1 & 2 & 4 \\
\hline 27 & & 0 & & 0 & & 0 & & 0 & & 0 & & 1 & & 0 & & 0 \\
\hline 28 & & 0 & & 0 & & 0 & & 0 & & 2 & & 0 & & 0 & & 0 \\
\hline 29 & & 0 & & 0 & & 0 & & 0 & & 1 & 2 & 3 & & 0 & & 0 \\
\hline 30 & & 0 & & 0 & & 0 & 1 & 2 & & 0 & & 1 & & 0 & & 0 \\
\hline 31 & & 0 & & 0 & & 0 & & 1 & & 1 & & 1 & & 0 & 1 & 1 \\
\hline 32 & & 0 & & 0 & & 0 & & 0 & & 0 & & 0 & & 0 & & 0 \\
\hline 33 & & 0 & & 0 & & 0 & & 0 & & 0 & & 0 & & 0 & & 0 \\
\hline 34 & & 0 & & 0 & & 0 & & 1 & & 1 & & 2 & & 0 & & 0 \\
\hline 35 & & 0 & & 0 & & 0 & & 0 & & 2 & & 4 & & 0 & & 0 \\
\hline 36 & & 0 & & 0 & & 0 & & 0 & & 0 & & 0 & & 0 & & 0 \\
\hline 37 & & 0 & & 0 & & 0 & & 0 & & 0 & & 4 & & 0 & & 0 \\
\hline 38 & & 0 & & 0 & 1 & 1 & & 0 & 1 & 10 & & 5 & & 0 & & 0 \\
\hline 39 & & 0 & & 0 & & 0 & & 0 & & 1 & & 0 & & 0 & & 0 \\
\hline 40 & & 0 & & 0 & & 0 & & 0 & & 0 & 1 & 1 & & 0 & & 0 \\
\hline 41 & & 0 & & 0 & & 0 & & 0 & & 0 & & 0 & & 0 & & 0 \\
\hline 42 & & 0 & & 0 & 2 & 8 & 1 & 2 & 2 & 28 & 14 & 58 & 3 & 7 & 2 & 3 \\
\hline 43 & 5 & 8 & & 1 & 3 & 15 & 4 & 14 & 14 & 91 & 32 & 143 & 10 & 23 & 3 & 17 \\
\hline 44 & & 0 & & 0 & & 0 & & 0 & & 0 & & 0 & & 0 & & 0 \\
\hline 45 & & 1 & & 0 & & 1 & & 1 & & 3 & & 3 & & 0 & & 0 \\
\hline 46 & & 0 & & 0 & & 0 & & 1 & & 5 & & 5 & & 0 & & 0 \\
\hline 47 & & 0 & & 0 & & 1 & & 0 & & 1 & & 0 & & 0 & & 0 \\
\hline 48 & & 0 & & 0 & & 3 & 1 & 3 & 1 & 8 & 7 & 15 & 1 & 2 & & 2 \\
\hline 49 & & 0 & & 0 & & 0 & & 0 & 1 & 4 & 1 & 1 & & 0 & & 0 \\
\hline 50 & & 0 & & 0 & & 0 & & 0 & & 0 & & 8 & & 0 & & 0 \\
\hline 51 & & 1 & & 0 & & 0 & & 0 & 2 & 10 & 4 & 2 & & 1 & & 1 \\
\hline 52 & & 0 & & 0 & & 0 & & 0 & & 0 & 2 & 0 & & 0 & & 0 \\
\hline 53 & & 0 & & 0 & & 0 & & 0 & & 0 & & 1 & & 0 & & 0 \\
\hline 54 & & 0 & & 0 & & 0 & 1 & 2 & & 0 & 1 & 0 & & 0 & & 0 \\
\hline 55 & & 0 & & 0 & & 0 & & 0 & & 0 & & 0 & & 0 & & 0 \\
\hline 56 & & 0 & & 0 & & 0 & & 0 & & 0 & & 0 & & 0 & & 0 \\
\hline 57 & & 0 & & 0 & & 0 & & 0 & & 0 & & 0 & & 0 & & 0 \\
\hline 58 & & 0 & & 0 & & 0 & & 0 & & 0 & & 0 & & 0 & & 0 \\
\hline 59 & & 0 & & 0 & & 0 & & 0 & & 2 & & 5 & & 0 & & 0 \\
\hline 60 & & 0 & & 0 & & 0 & & 0 & & 0 & & 0 & & 0 & & 0 \\
\hline 61 & & 0 & & 0 & & 0 & & 0 & & 0 & & 0 & & 0 & & 0 \\
\hline 62 & & 0 & & 0 & & 0 & & 1 & & 2 & & 0 & & 1 & & 0 \\
\hline Totales & 25 & 32 & 2 & 4 & 50 & 85 & 34 & 69 & 198 & 447 & 344 & 626 & 37 & 61 & 35 & 65 \\
\hline & (12) & (18) & $(0)$ & (2) & (10) & $(40)$ & $(10)$ & (41) & (37) & (267) & (73) & (331) & (17) & (40) & (9) & (37) \\
\hline
\end{tabular}

Tab. 8. Utensilios (según lista tipo de Bordes). (1): soportes Levallois. (2): total de los soportes. Los totales entre paréntesis se refieren a recuentos esenciales.

T. P., 55, n. $^{\circ} 1,1998$ 
centaje (Grupo IV: 34,1; Grupo IVa: 44,6). La evolución más notable se da en el llamado "grupo musteriense" (Grupo II) y especialmente en las raederas, que llegan a un valor mediano, pero expresivo (IR: 32,6 ), sobre todo a costa del aumento relativo de los tipos de características musterienses. Un dato especialmente curioso es el del aumento de las puntas hasta valores muy significativos: 5,2 \% (puntas Levallois + Levallois retocadas), 13,5\% (idem + puntas seudolevallois), $17,2 \%$ (idem + puntas de Tayac). Queda firmemente atestiguada, en este nivel, la intención de fabricar puntas. Es claro, por ejemplo, que diversos ejemplares de "puntas seudo-levallois" constituyen verdaderos utensilios potenciales, no sólo subproductos característicos de la talla centrípeta. A la vez, resulta obvia la intencionalidad de la mayor parte de las puntas de Tayac, que no pueden ser asimiladas de manera simplista a meros denticulados convergentes. En cuanto a la talla Levallois, verificamos una ligera reducción del índice tipológico correspondiente (ILty: 36,5), volviendo a aumentar los soportes llamados atípicos (cerca del 50\% de la suma atípicos + típicos).

Nivel 6a: con un total de 41 utensilios en cuenta esencial (ó 40, en los términos restrictivos indicados) ofrece pocas garantias de representatividad estadística. Aún así, tratándose de una capa poco espesa y bien encuadrada en la dinámica registrada a lo largo de la secuencia sedimentaria inferior, parece aceptable tomar en consideración algunos rasgos esenciales: la relación entre el grupo de los denticulados y el de las raederas se mantiene sensiblemente igual, con un nuevo ligero crecimiento de los segundos, deja de hacerse notar el grupo de las puntas, se mantiene un valor de ILty $(33,3)$ dentro de los parámetros que definen una "facies levalloisiense" y se reproduce una relación idéntica a la de los niveles inferiores entre elementos atípicos y típicos en el conjunto de talla Levallois.

Nivel 6: su total de 40 utensilios en cuenta esencial (ó 37, en los términos restrictivos indicados) es manifiestamente insuficiente para cualquier interpretación precisa, especialmente si consideramos el espesor de esta capa. Como quiera que sea, salvo la circunstancia de un valor ILty más elevado $(48,2)$, normal en industrias de facies Levallois, todos los indicadores de este conjunto mantienen las características y las tendencias evolutivas de los anteriores.

Nivel 4: La última capa con vestigios de ocupación humana incluye solamente un total de 18 utensilios en cuenta esencial (ó 17, en términos restrictivos), valores que apenas permiten sugerir cualquier comentario global, teniendo en cuenta el contexto que aportan los conjuntos líticos de las capas restantes. No se observa ningún indicador anómalo en relación con la estructura de los conjuntos subyacentes y, sobre todo, hay que señalar la completa ausencia de utensilios que puedan sugerir cualquier aproximación tipológica a los modelos del Paleolítico Superior.

De la breve caracterización que acabamos de realizar, pueden, finalmente, extraerse las siguientes ideas de conjunto (v. Tab. 7 y 8 ; Fig. 7 a 11):
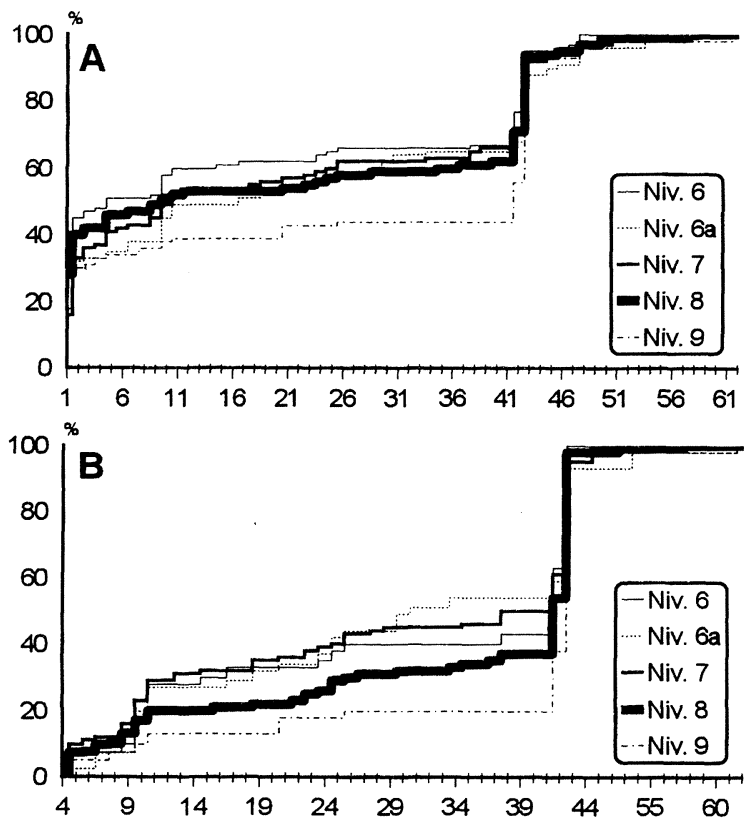

Fig. 8. A: Gráfico acumulativo real. B: Gráfico acumulativo esencial (según sistema Bordes).
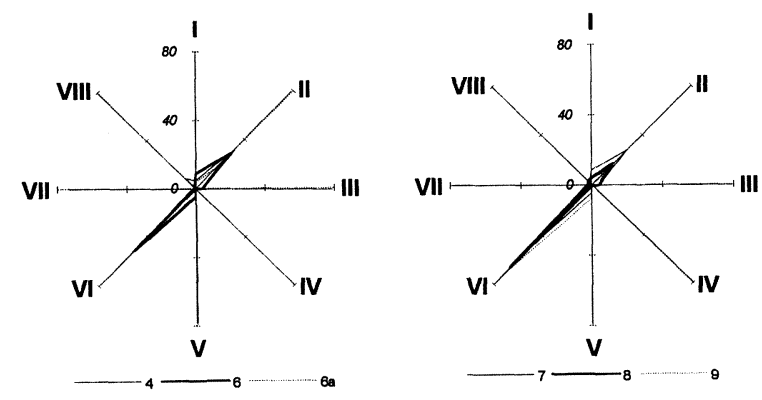

Fig. 9. Principales categorías tipológicas (según método de A. Turq). I: Puntas; II: Raederas simples y dobles; III: Raederas tipo Quina; IV: Tipo Musteriense. De tradición Achelense; V: Tipos Musteriense Ferrassie; VI: Denticulados y escotaduras; VII: Otros; VIII: Tipos Paleolítico Superior. 

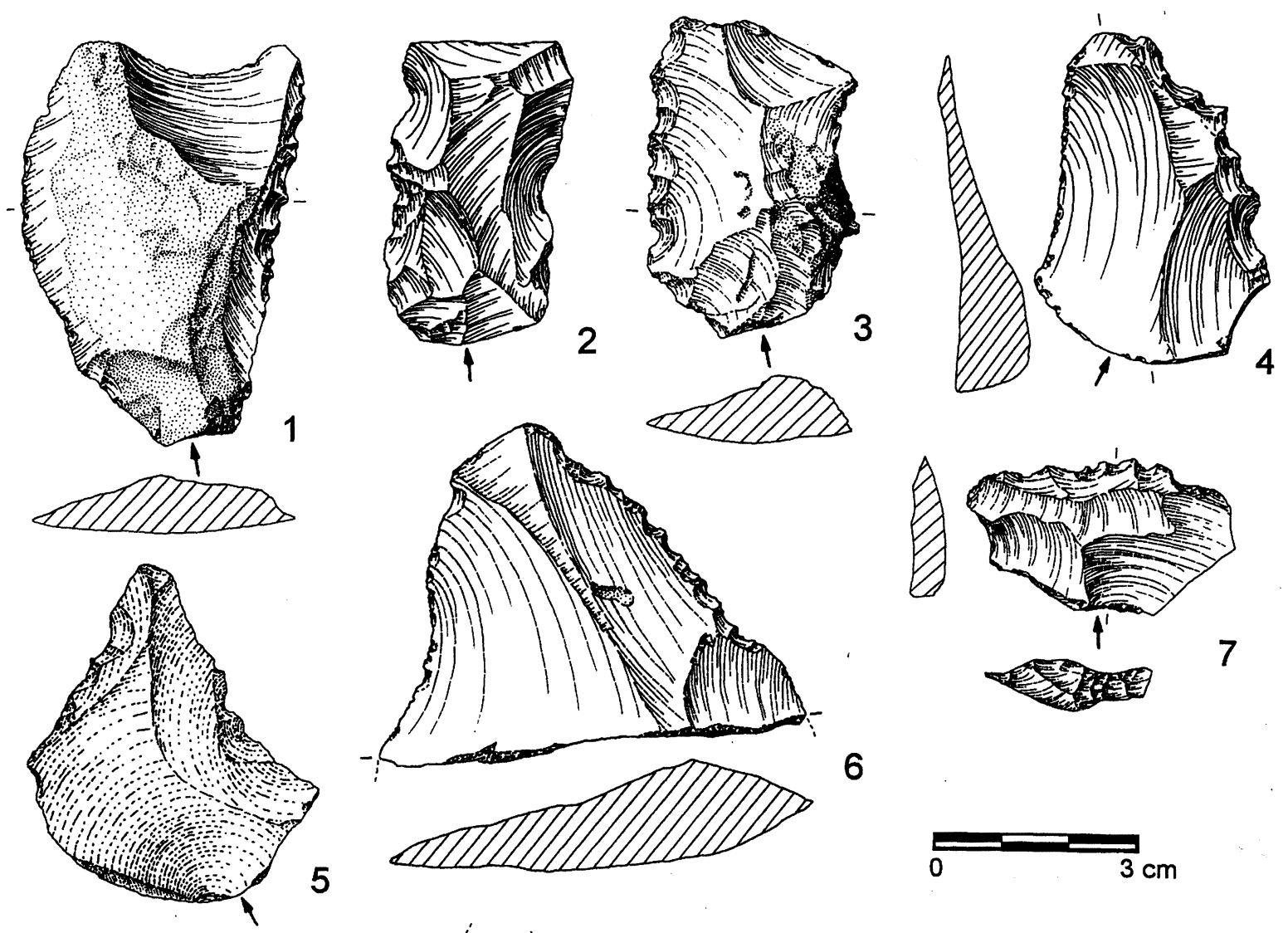

6
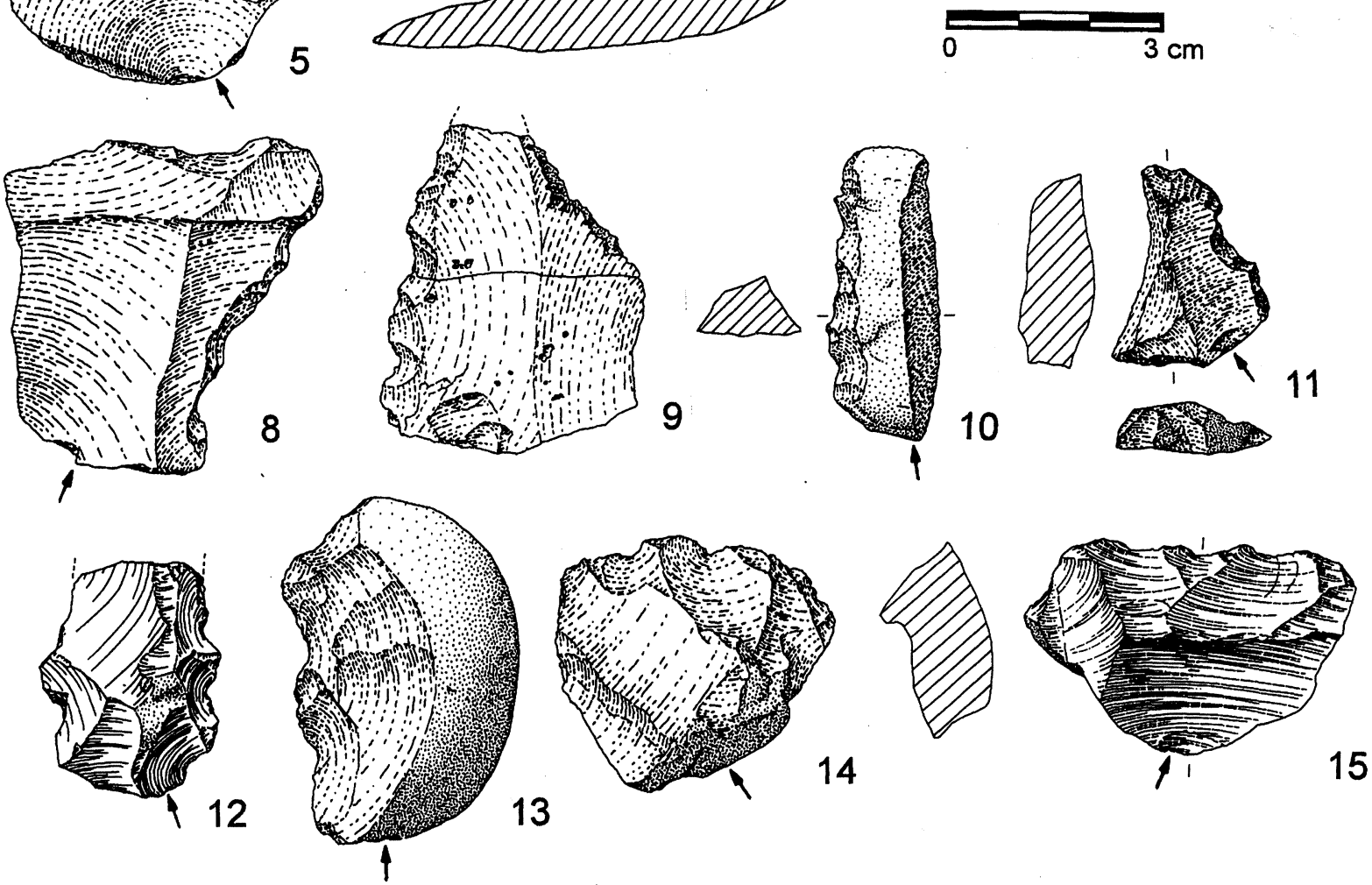

Fig. 10. Denticulados y escotaduras, 3-4, 6-7, 10-15: nivel 7; 2: nivel 6a; 5: nivel 6; 8-9: nivel 4). Todos denticulados, excepto el $n^{\circ} 11$, escotadura (1-2, 4. 6-7, 9, 12, 15: sílex; 13-14: cuarcita; 10: cuarzo). 


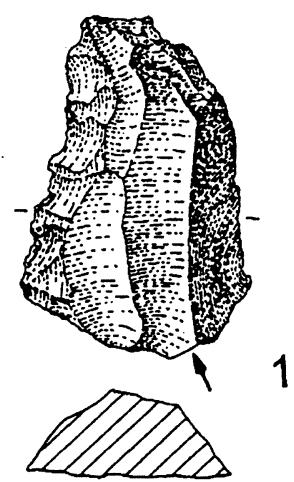

1
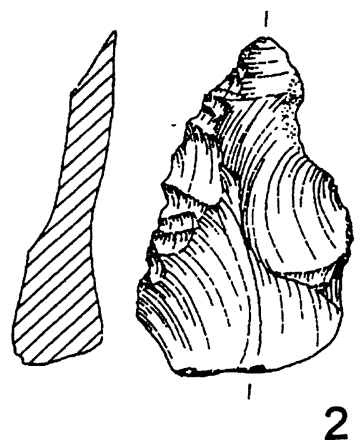

2
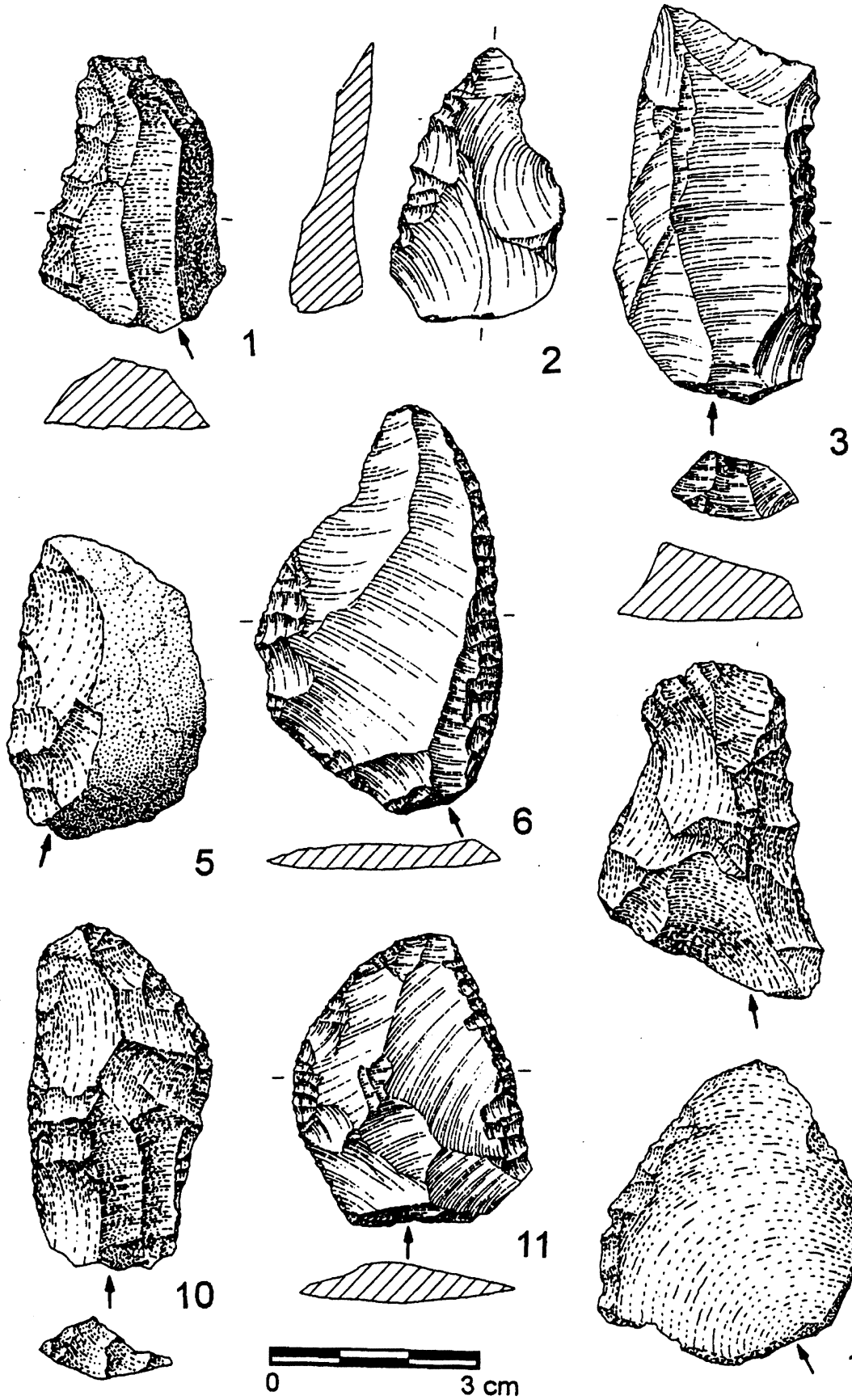

3
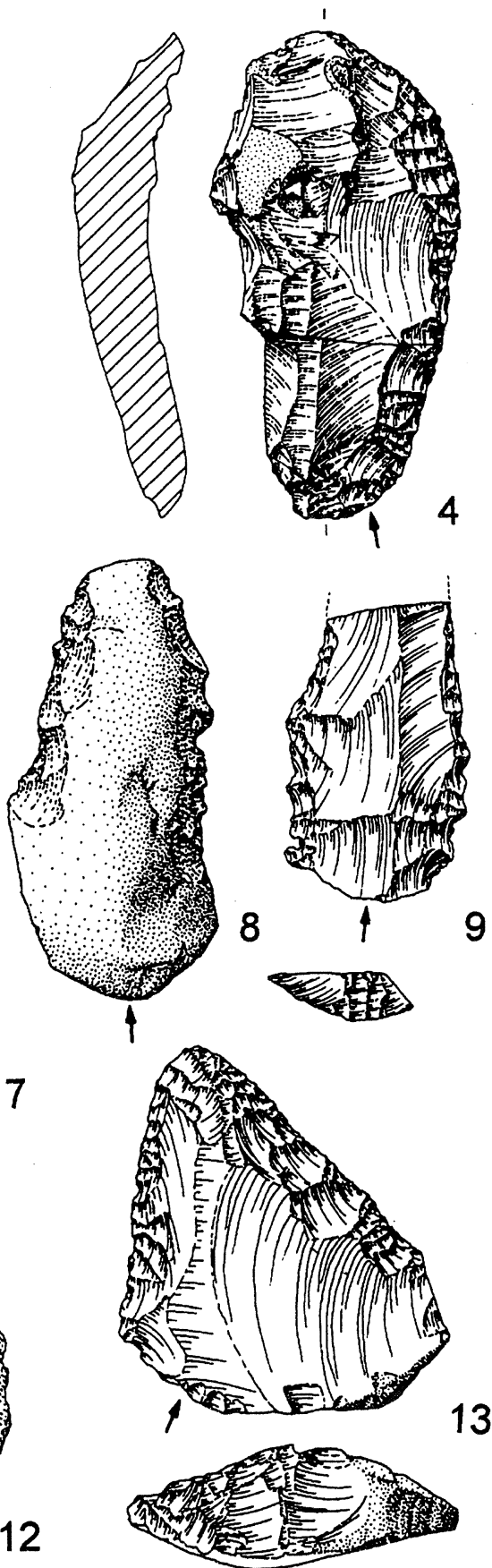

Fig. 11. Raederas (1-6, 8-12: nivel 7); 7: nivel 4; 13: nivel 6a). 13: raederas simples rectas; 4-6: raederas simples convexas; 7: raederas simples cóncavas; 8: raedera doble recto-convexa; 9: raedera doble biconvexa; 10: raedera doble recto-cóncava; 11-12: raederas convergentes convexas; 13 : raedera desviada $(1,5,8,10$ : cuarcita; 2-4, 6, 9, 11, 13: sílex, 7: cuarzo).

- De la base al techo, sin revelar cualquier tendencia evolutiva, las industrias líticas de esta gruta se sitúan ligeramente por encima de la definición técnica Levallois (IL:>c.15), conforme se- ñalamos en otro punto de este texto. Por otro lado, lo verificamos ahora, se integran plenamente en la llamada "facies levalloisense" (Ilty: $>30$ ).

- El grupo de denticulados (Grupo IV) domi-

T. P., 55, n. $^{\circ} 1,1998$ 
na casi siempre. Quizá pueda señalarse en el mismo una ligera tendencia a decrecer en términos relativos.

- El llamado "grupo musteriense" (grupo II), y dentro del mismo el subgrupo de las raederas, revela una destacada tendencia al crecimiento. Partiendo de valores bastante bajos, y siendo además dominadas por utensilios tipológicamente poco elaborados, comunes en las industrias del Paleolítico Inferior, alcanzan porcentajes significativos, aunque nunca elevados, siendo entonces dominadas por los tipos más característicos de las industrias del Paleolítico Medio.

- Lo que podríamos denominar "utillaje sobre bloque" está prácticamente ausente: los cantos tallados apenas están representados con algunos vestigios en los niveles 7 y 8 ; los utensilios bifaciales están pura y simplemente ausentes.

- De la misma manera, el utillaje de tipo Paleolítico Superior es escasísimo, dando lugar a valores del grupo III verdaderamente insignificantes, que además tienen una ligera tendencia a decrecer a lo largo de la secuencia sedimentaria.

- En general, el retoque de los filos para la elaboración de utensilios es muy limitado. Se constata una ausencia completa de retoques intensos, en concreto del estilo Quina o semi-Quina.

\section{CONCLUSIONES}

\subsection{Industria lítica}

Como vimos en los puntos anteriores, la ocupación de la Gruta Nova de Columbeira se traduce en la acumulación de una abundante industria lítica en el interior de la cavidad, casi seis millares de artefactos, que se concentra especialmente en las capas inferiores ( 9 a 7), pero se extiende también a las intermedias ( 6 a 4). El segmento superior de la secuencia sedimentaria (capas 3 a 1 ) no revela indicio alguno de frecuentación humana.

Algunos elementos sugieren la existencia de diferentes tipos de asentamiento humano en la gruta: visitas ocasionales, incluso durante períodos en que las asociaciones faunísticas están dominadas por los carnívoros, y ocupaciones intensas, ajustadas incluso al modelo de campamento-residencia base. En el primer caso se encuentran los niveles 9, 6a, 6 y 4; en el segundo estarían los niveles 8 y 7 . En términos muy simples podría decirse que después del descubrimiento inicial (nivel 9) por parte de grupos humanos que seguían patrones de explotación muy económicos de los soportes líticos disponibles (introducción en la gruta de nódulos en avanzado estado de formatización y rejuvenecimientos sucesivos de los filos activos de los utensilios), la cavidad fue enseguida usada como local de ocupación regular intensa (niveles 8 y 7), para pasar más tarde a ser un punto frecuentado sólo de vez en cuando (niveles $6 \mathrm{a}$ a 4). Esta evolución encuentra además correspondencia perfecta en la composición de las asociaciones faunísticas: en las capas de base llegan a ser cuantitativamente dominadas por los herbívoros, en las capas intermedias los carnívoros se instalan en mayor número, y en las superiores, ya sin presencia humana dentro de la cueva, cuando la abertura de entrada debía ser diminuta, los grandes mamíferos casi desaparecen y de forma correlativa aumentan las aves, inclusive las rapaces, con todo el cortejo de presas que normalmente aparecen asociadas a ellas.

A pesar de las diferencias registradas en las características de las ocupaciones humanas, del análisis de los conjuntos líticos resalta, como idea de fondo, su gran estabilidad estructural a lo largo de toda la secuencia estratigráfica. En el plano de la gestión de las materias primas, el sílex, el cuarzo y la cuarcita constituyen las rocas dominantes, sin que se de un aprovisionamiento sistemático de ninguna de ellas en especial. En el dominio técnico, las tendencias evolutivas de todos los índices calculados (IL, ILam, IF) se expresan gráficamente por líneas rectas. En cuanto a los aspectos tipológicos, los denticulados y escotaduras, siempre dominantes, constituyen, junto a las raederas, la casi totalidad de los utensilios. Hay que destacar la completa ausencia de utillaje bifacial, así como la presencia apenas residual de piezas de tipo $\mathrm{Pa}$ leolítico Superior. De arriba a abajo, los conjuntos líticos de la Gruta Nova de Columbeira documentan con exactitud aquello que en la terminología bordiana tradicional podría ser designado Musteriense de denticulados rico en raederas, de talla y facies levallois (Fig. 10 a 12).

En cualquier caso, la estabilidad estructural indicada no es incompatible con la identificación de algunas tendencias evolutivas menores, también significativas. En el plano de la gestión de las materias primas, se comprueba un incremento en la adquisición de sílex, en detrimento del cuarzo. Ya en el ámbito de los métodos de talla, el grupo de los núcleos discoides y levallois asciende progre- 

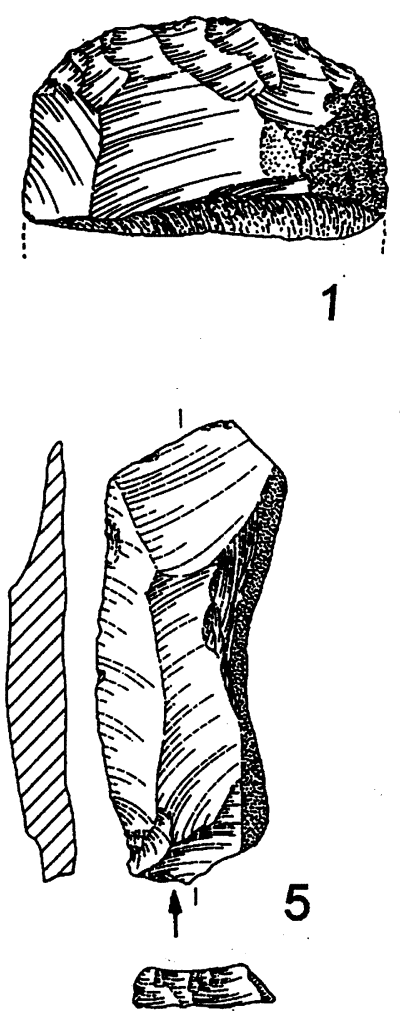

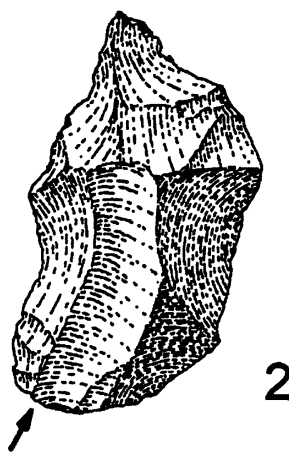

2

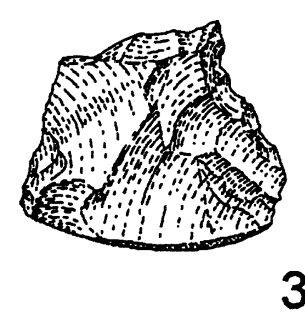

3
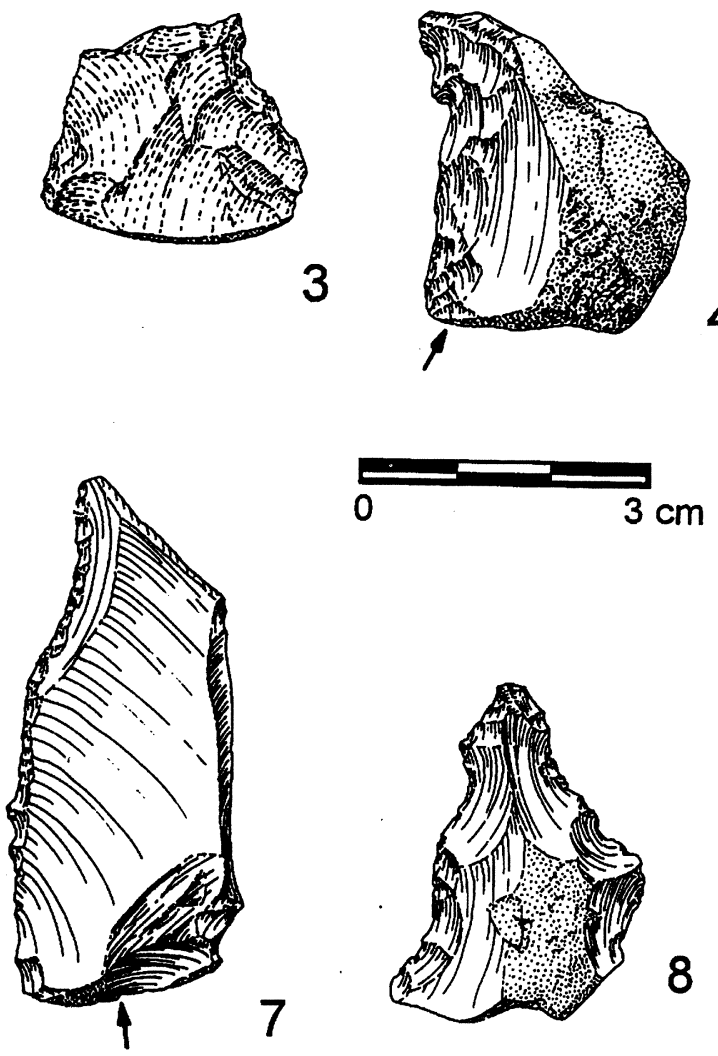

$3 \mathrm{~cm}$

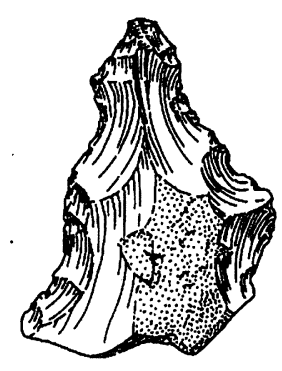

8

Fig. 12. Otros utensilios (1, 3, 7: nivel 6a; 4-6: nivel 7; 8: nivel 4). 1: raspador típico; 2-3: perforadores típicos; 4: perforador atípico; 5-6: cuchillos de dorso natural; 7: lasca con retoque abrupto; 8: punta de tayac (1, 4-5, 7-8: sílex; 2, 6: cuarcita; 3: cuarzo).

sivamente sobre las formas más primitivas. Desde un punto de vista tipológico, los porcentajes de raederas se revelan en crecimiento contínuo. Se registran otras particularidades, como la fabricación no fortuita de puntas, entre las que se aprecia un conjunto muy característico de puntas de Tayac, en el nivel 7.

Cuando se contrastan estas tendencias evolutivas, resulta patente la inexistencia de cualquier proximidad a patrones industriales de tipo Paleolítico Superior. Bien al contrario, todos los conjuntos industriales de la Gruta Nova de Columbeira parecen testimoniar algo que, utilizando una expresión muy en boga, se podría denominar "proceso de musterienización", expresado por indicadores como el aumento del nivel de aprovechamiento -de transfomación en utensilios- de las materias primas distintas del sílex, por la importancia creciente de los núcleos volumetricamente concebidos en términos de dos superficies opues- tas, y dentro de ellos de los núcleos Levallois, por el crecimiento de la sección de las raederas -y del llamado "Grupo Musteriense" en general-, con disminución relativa de los tipos frecuentes en las industrias achelenses y desarrollo de las formas comunes en las industrias musterienses.

\subsection{Contexto cultural}

La caracterización tecno-tipológica a que llegamos sugiere un amplio conjunto de comentarios en relación con la problemática de la inclusión de estas industrias en contextos culturales más amplios. Una vez excluida por el estudio tecno-tipológico realizado (y también por argumentos geoclimáticos que no es posible desarrollar en esta ocasión) la hipótesis de la presencia de horizontes culturales atribuibles al Paleolítico Superior, la problemática de la cronología de estos niveles del 
Paleolítico Medio, conforme a las dataciones radiométricas obtenidas por Jean Roche al final de los años 60, adquiere una gran relevancia. Estas fechas son las siguientes:

$$
\begin{aligned}
& \text { Gif-2703 } 26400 \pm 750 \text { BP (niv. 7) } \\
& \text { Gif-2704 } 28900 \pm 950 \text { BP (niv. 8) }
\end{aligned}
$$

$\mathrm{Al}$ intentar su análisis se comprenden bien las dudas que asaltaron a Roche, quién nunca llegó a publicarlas. En el marco de conocimientos de aquel momento no era posible dejar de considerar que estas dataciones eran "demasiado recientes" para un Musteriense cuyo límite superior se colocaba más o menos en 34-35 millares de años. Todas o casi todas las dataciones radiométricas son susceptibles de discusión y negación, si para ello hay argumentos adversos poderosos, y este parecía ser el caso. En función de tal presunción, se procuró argumentar en dos direcciones: o el diagnóstico de las industrias era erróneo y se trataba de un Paleolítico Superior Inicial, o las muestras utilizadas para la datación, "restos carbonosos", estaban contaminadas y rejuvenecidas por elementos procedentes de los niveles superiores. Sin embargo parece cierto que la coherencia estratigráfica, el grado de precisión y el propio resultado de las dataciones, que no es disparatado del todo, las hicieron más objeto de dudas que de una negación pura y simple.

Por nuestra parte reconocemos también que sería deseable disponer de un cuadro de dataciones absolutas más completo, recurriendo en la medida de lo posible al cruce de métodos diferentes. En este sentido, uno de nosotros (L.R.) promovió la datación de cuatro muestras faunísticas (dientes) por el método de las series de uranio $(\mathrm{Th} / \mathrm{U})$, obteniendo los resultados siguientes:

SMU-23851 $54365-27525+2224$ (cam. 7)

SMU-235E1 $35876-35583+27299$ (cam. 7)

SMU-236E1 $101487-55919+38406$ (cam. 8)

SMU-236E1 60927-35522+27405(cam. 8)

Se intentaron otros ensayos de datación por C14-AMS y por TL/OSL, sin éxito en ambos casos. Así, a partir de los datos existentes podemos concluir por ahora: a) Difícilmente se puede esperar obtener resultados mediante la aplicación del método TL/OSL a la datación de los sedimentos de esta gruta, dada su escasa exposición a la luz una vez depositados. b) Los valores Th/U obtenidos por uno de nosotros (L.R.) son inutilizables debido a sus enormes márgenes de error, compatibles en todo caso con las dos dataciones iniciales por $14 \mathrm{C}$, las únicas que existen. c) Sólo puede concederse significado real a las dos fechas $14 \mathrm{C}$ disponibles.

Al no haber dificultades geo o bioestratigráficas que desaconsejen su validez, queda sólo el argumento cultural: aceptarlas significa reconocer la extensión de las industrias musterienses hasta los 28-27 mil años y también, lo que es más importante aún, que las poblaciones neandertales hayan subsistido hasta esa misma época. Tal conclusión circunstancialmente se encuentra documentada por el diente de aquel tipo encontrado en la gruta, pero sobre todo está soportada por la certidumbre de que en el territorio ibérico hay una asimilación completa entre industrias musterienses y poblaciones neandertales. ¿Sería eso imposible o siquiera poco probable? La investigación en curso de unó de nosotros (L.R.) se centra en este dominio, por lo que nos limitaremos en esta ocasión a presentar los elementos mínimos que permitan examinar el asunto con una perspectiva general, imprescindible para una correcta interpretación de las industrias del yacimiento aquí estudiado. Mientras que en los años 70 nada hacia suponer que este tipo de supervivencias pudiera haber ocurrido, la investigación de las dos últimas décadas ha acumulado pruebas que, en nuestra opinión, demuestran de manera irrefutable que ha sido así.

La lista de los sitios ibéricos en que se han registrado horizontes culturalmente atribuidos al Paleolítico Medio, en varios casos con restos físicos de neandertales, datados de hace menos de treinta y cinco mil años (Fig. 13 y Tab. 9), resulta ya demasiado extensa para que pueda ser ignorada. Aunque es cierto que las dataciones propuestas para alguno de ellos pueden ser objeto de discusión, existen otros en los que las atribuciones cronológicas, realizadas a partir de criterios diferentes, a veces cruzados, son bastante sólidas. Sirvan de ejemplos, en España, las cuevas de Carihuela, Horá y Zafarraya, las de Gibraltar, así como las de Figueira Brava (Antunes, 1990-91; Cardoso y Raposo, 1993) y el yacimiento al aire libre de Foz de Enxarrique (Raposo et alii, 1985; Raposo, 1993a y 1995), en Portugal. Se confirman ahora, con elementos de datación dignos de todo crédito, las hipótesis que algunos autores vienen sugeriendo desde hace años a partir de argumentos geo y bioestratigráficos (Vega Toscano, 1990 y 1993). 


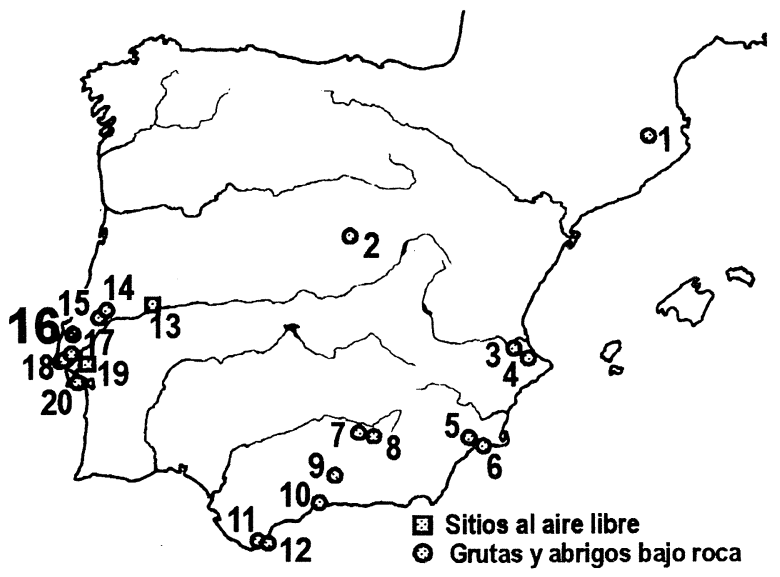

Fig. 13. Localización de los sitios incluidos en la tabla 9.

Está aún por hacer sin embargo el estudio comparativo de las industrias líticas de los sitios citados en el párrafo anterior. Aparentemente revelan una gran variabilidad, aunque con un notable rasgo común: en ninguna localidad -quizás con la excepción de Zafarraya, que por otro lado carece de estudio y publicación extensa- se llegó a detectar cualquier tipo de "industria de transición" hacia el Paleolítico Superior. Por el contrario, tal como ocurre en Gruta Nova de Columbeira, las industrias musterienses finales del Sur o del Occidente ibéricos atestiguan repetidamente una acentuación de los patrones musterienses, una "musterienización", aunque casi siempre dentro de estrategias de aprovisionamiento de materias primas, gestión de soportes y fabricación de utensilios marcadamente expeditivos.

Para intentar evaluar de manera correcta la realidad ibérica no es posible prescindir de un encuadramiento geográfico e histórico más amplio. Si observamos el mapa de Europa en tres momentos cronológicos sucesivos vemos el siguiente panorama:

\begin{tabular}{|c|c|c|c|c|c|c|}
\hline$N^{o}$ & Sitio & Región & Estratig. & Dataciones & Método & Obs. \\
\hline 1 & Ermitons & Girona & niv. IV & $33190+-660$ & C14AMS & (C14 convencional: $36430+-1800)$ \\
\hline 2 & Jarama VI & Guadalajara & niv. 2 & $29599+-2700$ & $\mathrm{C} 14$ & \\
\hline 3 & Cova Negra & Valencia & niv. 5 & $<30000$ & & estratigrafía \\
\hline 4 & Beneito & Alicante & $\mathrm{X}(\mathrm{D} 1)$ & $30160+-680$ & C14 & (C14 AMS: $38800+-1900)$ \\
\hline 5 & Perneras & Murcia & A-B & c. $29 / 30000$ & & estratigrafía \\
\hline 6 & Palomarico & Murcia & niv. medio & c. $29 / 30000$ & & estratigrafía \\
\hline 7 & Carihuela & Granada & $\begin{array}{l}\text { niv. IV } \\
\text { niv. V } \\
? \\
? \\
?\end{array}$ & $\begin{array}{l}\text { c. } 25000 \\
\text { c. } 30000 \\
\text { c. } 28000 \\
\text { c. } 32000 \\
\text { c. } 31-35000\end{array}$ & $\begin{array}{l}\text { TL } \\
\text { TL } \\
\text { TL }\end{array}$ & $\begin{array}{l}\text { estratigrafía y microfauna } \\
\text { estratigrafía y microfauna }\end{array}$ \\
\hline 8 & Horá & Granada & niv. II-VI & $<30000$ & & estratigrafía \\
\hline 9 & Zafarraya & Granada & $\begin{array}{l}\text { niv. I-3/7 } \\
\text { id. } \\
\text { id. } \\
\text { id. } \\
\text { niv. I-8 } \\
\text { id. } \\
\text { niv. D }\end{array}$ & $\begin{array}{l}25100+-1300 \\
26900+-2700 \\
28900+-4200 \\
29800+-600 \\
31700+-3600 \\
31800+-550 \\
33400+-200\end{array}$ & $\begin{array}{l}\text { Th/U } \\
\text { Th/U } \\
\text { Th/U } \\
\text { C14 } \\
\text { Th/U } \\
\text { C14 } \\
\text { Th/U }\end{array}$ & niv. con neandertales \\
\hline 10 & Bajondillo & Torremolinos & niv. base & $\begin{array}{l}25300 / 26500+-10 / 15 \% \\
27300+-1700\end{array}$ & $\begin{array}{l}\mathrm{ESR} \\
\mathrm{Th} / \mathrm{U}\end{array}$ & $\begin{array}{l}\text { datacíon sobre travertino } \\
\text { idem }\end{array}$ \\
\hline 11 & Devil's Tower & Gibraltar & $\begin{array}{l}\text { niv } 3 \\
\text { niv. } 4\end{array}$ & $\begin{array}{l}>30000 \\
\text { c. } 29000\end{array}$ & $\begin{array}{l}\text { C14 } \\
\text { C14 }\end{array}$ & datacíon niño neandertal \\
\hline 12 & Gorham Cave & Gibraltar & $\begin{array}{l}\text { niv. } \mathrm{G} \\
\text { niv. } \mathrm{G}\end{array}$ & $\begin{array}{l}47700 ; 49200 \\
<30000\end{array}$ & $\mathrm{C} 14$ & $\begin{array}{l}\text { fechas discutibles } \\
\text { estratigrafía }\end{array}$ \\
\hline 13 & Foz Enxarrique & Ródão & niv. C & $\begin{array}{l}32938+-1055 \\
34088+-800 \\
34093+-920\end{array}$ & $\begin{array}{l}\text { Th/U } \\
\text { Th/U } \\
\text { Th/U }\end{array}$ & horizonte paleolítico único \\
\hline 14 & Caldeirão & Tomar & niv. $\mathrm{K}$ & $27600+-600$ & $\mathrm{C} 14$ & o P. Superior inicial \\
\hline 15 & Lapa dos Furos & Tomar & $\begin{array}{l}\text { niv. } 4 \\
\text { niv. } 4\end{array}$ & $\begin{array}{l}30570+-760 \\
34580+1160-1010\end{array}$ & $\begin{array}{l}\text { C14 } \\
\text { C14 }\end{array}$ & $\begin{array}{l}\text { sobre brecha - interest. Würm } \\
\text { idem }\end{array}$ \\
\hline 16 & Columbeira & Bombaral & $\begin{array}{l}\text { niv. } 16 \\
\text { niv. } 20\end{array}$ & $\begin{array}{l}26400+-750 \\
28900+-950\end{array}$ & $\begin{array}{l}\text { C14 } \\
\text { C14 }\end{array}$ & \\
\hline 17 & Salemas (Algar) & Loures & $\begin{array}{l}\text { niv. inferior } \\
\text { id. } \\
\text { id. }\end{array}$ & $\begin{array}{l}27170+1000-900 \\
>29200 \\
29890+1130-980\end{array}$ & $\begin{array}{l}\text { C14 } \\
\text { C14 } \\
\text { C14 }\end{array}$ & \\
\hline 18 & Pêgo do Diabo & Loures & niv. 2-base & $28120+-860$ & $\mathrm{C} 14$ & base de nivel del P. Superior \\
\hline 19 & Conceição & Alcochete & niv. C-techo & $27200+-2500$ & TL/OSL & \\
\hline 20 & Figueira Brava & Sesimbra & $\begin{array}{l}\text { niv. inferior } \\
\text { niv. indet. }\end{array}$ & $\begin{array}{l}30050+-550 \\
30930+-700\end{array}$ & $\begin{array}{l}\mathrm{C} 14 \\
\mathrm{C} 14\end{array}$ & \\
\hline
\end{tabular}

Tab. 9. Principales yacimientos del Paleolítico Medio Final de la Península Ibérica ( $<35000$ años).

T. P., 55, n. $^{\circ} 1,1998$ 

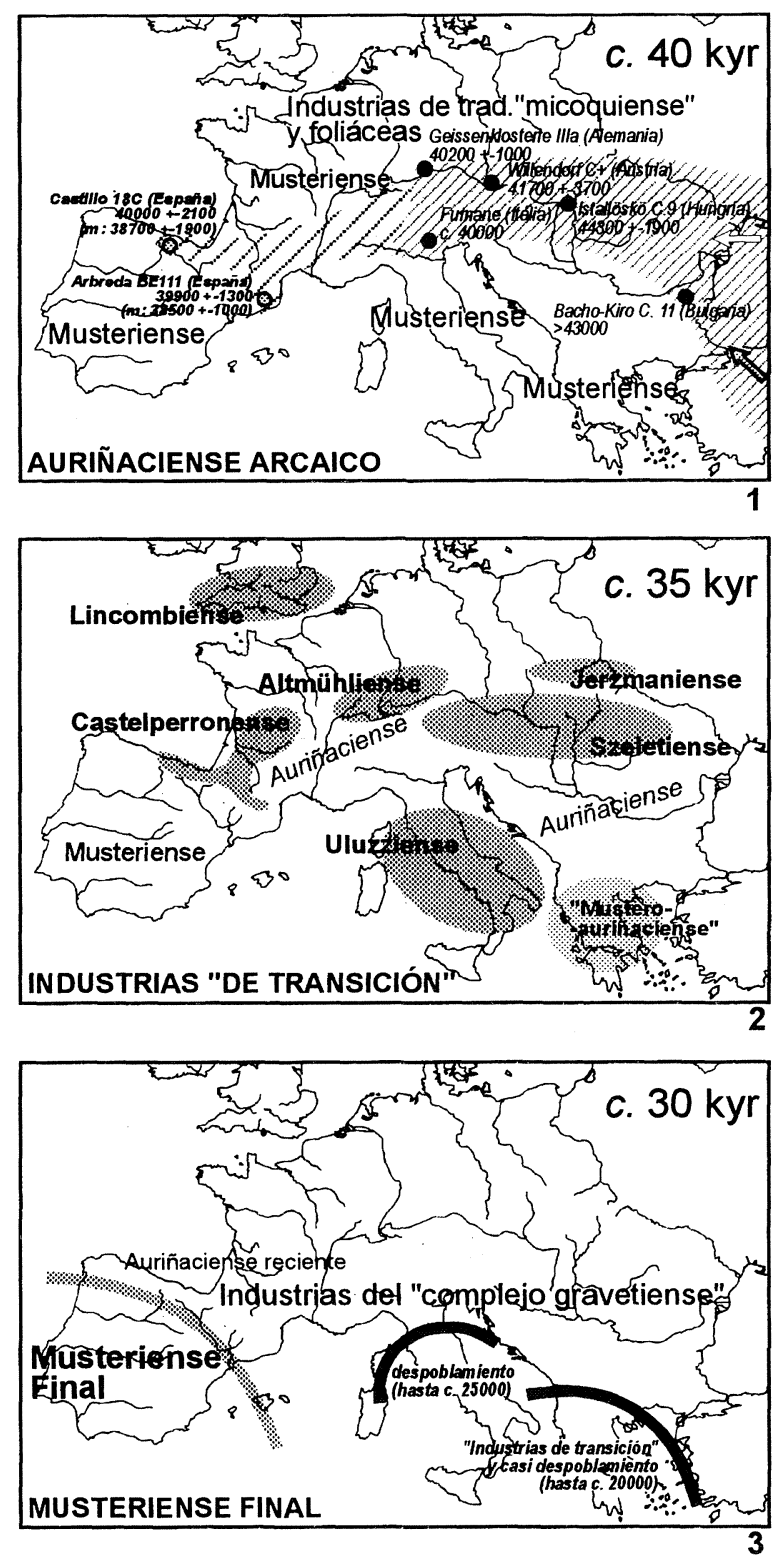

Fig. 14. Distribución del Auriñaciense Arcaico (1), de las "industrias de transición" (2) y del Musteriense Final (3) en Europa.

- Hace cerca de cuarenta mil años, o incluso antes (Fig. 14.1), las primeras industrias del Paleolítico Superior (Auriñaciense) parecen ocupar una faja latitudinal relativamente estrecha, constituyendo un "frente" que, con origen al Este (Bacho-Kiro, niv. 11), ocupa Europa Central a lo largo del valle del Danubio (Istallöskö, niv. 9; Willendorf $\mathrm{n}+$; Geissenklosterle IIIa) y del arco alpino (Abri de Fumane), extendiéndose eventual- mente -si aceptamos las respectivas dataciones, lo que no está exento de controversia- hasta Cataluña (Arbreda BE111) y Cantabria (Castillo 18C). En la periferia no se registran "industrias de transición" significativas. Las de tipo foliáceo o laminar, respectivamente en Alemania y en el Norte de Francia/Bélgica, no pueden ser asimiladas a este concepto ya porque, si en efecto existieron como en el primer caso, constituían el desarrollo de antiguas tradiciones autóctonas, o porque, en el segundo caso, sólo se documentan muchas decenas de milenios antes, y no pueden ser invocadas en este contexto.

- A partir de hace unos treinta y cinco mil años (Fig. 14.2), se multiplican las llamadas "industrias de transición", especialmente en los márgenes de la anterior faja latitudinal auriñaciense. Sin que pretendamos discutir aquí el significado histórico de tales industrias, y recusando en especial la simplificación de interpretarlas todas por igual, no dejamos de señalar la fuerte impresión de aculturación que algunas sugieren. Difícilmente se comprendería de otro modo como, sin inmediatas raíces locales, poblaciones geográficamente tan diversas convergieron casi de repente hacia los patrones tecno-tipológicos definidores del Paleolítico Superior. Interesa de todas maneras subrayar que "aculturación" no significa "difusionismo" generalizado, ni mucho menos "inferioridad" biológica o cultural. Debe entenderse nada más que como la forma más económica de interpretar los datos existentes, haciendo uso del mecanismo más universal mediante el cual las innovaciones, y en especial las tecnológicas, se extienden. Resta aún anotar la situación existente en este momento en el área mediterránea: "industrias de transición" en las penínsulas itálica (Uluziense) y balcánica, aunque aquí mal documentadas y sincréticamente reunidas en un vago concepto de conjuntos "mustero-auriñacienses", y mantenimiento del Musteriense en Iberia, al sur del sistema Ebro/Cordillera Cantábrica.

- En torno a los treinta mil años e incluso después (Fig. 14.3), las industrias del Paleolítico Superior se extienden por Europa, habiendo prácticamente desaparecido las llamadas "industrias transicionales". Apenas las tres penínsulas meridionales revelan un comportamiento peculiar. En las dos orientales parece observarse un despoblamiento casi total del territorio, no justificable ni por falta de investigación, ni por cualquier clase 
de adversidad ambiental (3). La más occcidental revela, como se ha indicado ya, una perduración importante de las industrias musterienses.

La confirmación de la permanencia hasta muy tarde, hasta los 30-28/27 mil años por lo menos, de poblaciones neandertalenses e industrias musterienses en gran parte de la Península Ibérica no ofrece hoy contestación apreciable. Importaría ahora poner a punto los modelos que permitiesen explicar esta situación, lo que según creemos sólo puede hacerse desde la perspectiva pan-europea que de forma somera acabamos de dibujar. De acuerdo con las concepciones en elaboración por uno de nosotros (L.R.), la comprensión plena de los datos ibéricos requiere ser abordada desde una perspectiva más amplia, basada en una interpretación paleobiogeográfica de la entidad neandertalense (Hublin, 1990), en su origen, en su desarrollo diversificado y ... en su extinción. Nos encontramos en un terreno de investigación en el que se torna necesario verificar la diversidad de ambientes paisajísticos y climáticos de Europa en el período que va desde el final de la penúltima glaciación hasta el comienzo de la "degradación climática" que anuncia el último máximo glaciar; un campo de estudio en el que, teniendo en cuenta ese tipo de factores mesológicos y la misma configuración geográfica del continente, importa proceder a una contrastación de las condiciones que favorecen el arraigo de endemismos en las diferentes regiones de Europa, especialmente en las penínsulas meridionales. Con base en estos datos y en una rigurosa datación de algunos hallazgos antropológicos clave, sería tal vez posible controlar la realidad de una insospechada variedad biológica y la potencialidad adaptativa en aquello que sincreticamente se ha designado como "neandertales". Se podría quizás, por ejemplo, reconstruir la antigua idea de Sergio Sergi acerca de la existencia de una variedad neandertalense mediterránea, más indiferenciada y grácil que la variedad considerada clásica, idea a la que han regresado sucesivamente otros autores, si bien con grandes dudas por falta de un soporte cronológico adecuado. En 1982 Anne-Marie Tillier concluía su estudio sobre los ejemplares infantiles neandertalenses de Devil's Tower sugiriendo que los rasgos

(3) Véanse al respecto las importantes comunicaciones sobre el tema presentadas por Margherita Mussi y Catherine Perlès en el «workshop» de Dolni Vestonice promovido por la European Science Foundation, en prensa actualmente: Mussi y Roebroeks, 1996.

T. P., 55, n. ${ }^{\circ} 1,1998$ plesiomorfos detectados en ellos podrían deberse a una eventual edad pre-würmiense -explicación igualmente utilizada para la interpretación de caracteres idénticos en algunos fósiles italianos y del oriente de Europa-, aunque admitía ya entonces que si par contre les fossiles de Gibraltar sont plus récents (dernière glaciation) comme le suposait Garrod, ils constitueraient les seuls représentants en Europe d'une variété néanderthalienne isolée géographiquement (Tillier, 1982: 147). En 1991, Silvana Condemi, al comprobar las características plesiomorfas del cráneo de Monte Circeo 1, semejantes a las de los fósiles de Saccopastore -fechados en el último periodo interglaciar- y bastante diferentes de las poblaciones neandertalenses clásicas -dominadas por caracteres apomorfos-, concluía también que, admitiendo la datación reciente, würmiense, de Circeo 1, it would be tempting to interpret this difference in terms of a local continuity particular to each of these two geographic regions (Condemi, 1991: 353). Más recientemente, Giorgio Manzi y colaboradores, al proceder al análisis de nuevos restos neandertalenses de Monte Circeo, procedentes de la Grotta Breuil, afirman que los rasgos de gracilidad detectados en él are best considered as the expression of geographic (and adaptative) variation (Manzi et alii, 1995: 359). Así, las recientes dataciones radiométricas de los horizontes musterienses y de los restos neandertales de Monte Circeo, en Italia, y en particular los de Devil's Tower (Tab. 9), en Gibraltar, si verdaderos y confirmados por el estudio antropológico de otros hallazgos, los de Zafarraya entre ellos, adquieren en este contexto una importancia crucial: confirmarían en definitiva la existencia de una variedad neandertal mediterránea, más indiferenciada y potencialmente progresiva que la variante "clásica".

$\mathrm{Si}$ a todo el escenario descrito añadimos las condiciones de aislamiento y la dimensión geográfica de cada una de las tres penínsulas meridionales de Europa, tenemos abierto el camino para la explicación de la supervivencia de las poblaciones neandertalenses en Iberia hasta después de los treinta mil años, así como también para el aparente despoblamiento casi total de Italia y Grecia desde esos momentos hasta cerca de los veinticinco mil años. La no ocupación precoz del Centro, Sur y Occidente de la Península Ibérica por parte de las primeras poblaciones biológicamente modernas, en torno a los cuarenta mil años, y la frecuentación fugaz de ellas que se señala en Italia y la 
península balcánica, pueden obedecer a la acción combinada de dos factores: la eventual dificultad de adaptación a los respectivos ambientes naturales y, sobre todo, a la circunstancia de que dichos ambientes estaban ocupados ya por poblaciones biológicamente progresivas (no en el sentido de una aproximación a la entidad sapiens sapiens, sino en una consideración estrictamente biológica y dentro de un marco de referencia neandertalense), si bien tecnológica y culturalmente menos evolucionadas. En estos términos sería de esperar que la dimensión de los territorios respectivos jugase un papel decisivo: territorios más pequeños y geográficamente accesibles habrían podido originar todo tipo de fenómenos de aculturación y/o disminución rápida de la población, junto a la extinción de los grupos menos equipados. Territorios mayores y geográficamente más inaccesibles suscitarían el mantenimiento de rasgos culturales propios y la perduración de las poblaciones antiguas, que dispondrían de territorios reproductivos suficientemente vastos. Creemos que así se pueden haber desarrollado los acontecimientos en Oriente (Grecia, Italia) y en Occidente (Portugal y España mediterránea). Las asociaciones faunísticas propias de cada región, especialmente en el caso ibérico, donde se documenta una antigua megafauna relicta hasta periodos muy recientes -destaca la presencia de Elephas antiquus próximo a 30.000 años en Foz de Enxarrique (Raposo et alii, 1985)-, después radicalmente sustituida por una fauna banal, de tipo moderno, prueban los endemismos, constituyendo la población neandertalense un elemento más de una historia cuya completa explicación requiere su inclusión en este amplio cuadro geográfico y natural.

La Gruta Nova de Columbeira puede, así, inscribirse mejor en un contexto regional y europeo en el que adquiere todo su significado. No escondemos que sería deseable obtener en ella un mayor número de dataciones radiométricas. Pero incluso si en el futuro tales dataciones "envejecieran" en alguna medida el Musteriense de esta localidad, no quedaría mínimamente perjudicada la argumentación global acerca del Musteriense Final ibérico y la explicación histórico-antropológica aquí esbozada. Con ironía, diríamos que no habría más que sustraer un punto al mapa de los sitios de aquella banda cronológica, y pasar a encarar el "proceso de musterienización" de la Gruta Nova de Columbeira como un desarrollo de larga duración, inmune a presupuestos historicistas que re- chazamos, pero que una secuencia rápida como la que describimos inevitablemente instala en nuestros espíritus.

\section{BIBLIOGRAFÍA}

Antunes, M. Telles (1990-91): "O Homem da Gruta da Figueira Brava (ca. 30000 BP)". Memórias da Academia das Ciências de Lisboa, Classe Ciências, 31: 487-536. Lisboa.

CARDoso, J.L. (1993): Contribuição para o conhecimento dos Grandes Mamíferos do Plistocénico Superior de Portugal. Ed. Câmara Municipal de Oeiras. Oeiras.

Cardoso, J.L. y Raposo, L. (1993): “As indústrias paleolíticas da Gruta da Figueira Brava (Setúbal)", Actas da $3^{a}$ Reunião do Quaternário Ibérico: 451-456. Coimbra.

Comdemi, S. (1991): "Circeo 1 e la variabilità dei neandertaliani classici". Il Cranio Neandertaliano Circeo I. Studi e Documenti. Roma: 339-355.

FEREMBACH, D. (1964-65): "La molaire humaine inférieure moustérienne de Bombarral (Portugal)", Comunicações dos Serviços Geológicos de Portugal, 48: 185-190.

Ferreira, O. dA Veiga (1966): "Acerca dos primeiros restos de Homo Neanderthalensis encontrados no Mustierense de Portugal". Lucerna, 5: 361-375.

- (1984): "O mais importante nível de ocupação do caçador neandertal da Gruta Nova da Columbeira (Bombarral)". Volume d'hommage au géologue G. Zbyszewski. Ed. Recherche sur les Civilisations. Paris: 365-370.

Hublin, J.-J. (1990): "Les peuplements paléolithiques de l'Europe: un point de vue paléobiogéographique". Mémoires du Musée de Préhistoire d'Ile de France, 3: 29-37. Némours.

Hublin, J.-J.; Barroso Ruiz, C.; Medina Lara, P.; FonTUGNE, M. y REYss, J.-L. (1995): “The Mousterian site of Zafarraya (Andalucia, Spain): dating and implications on the palaeolithic peopling processes of Western Europe". Compte Rendu de l'Académie des Sciences de Paris, 321-2a: 931-937.

Manzi, G. y Passarello, P. (1995): "At the Archaic/Modern Boundary of the Genus Homo: The Neandertals from Grotta Breuil". Current Anthropology, 36 (2): 355-366.

Mussi, M. y Roebroeks, W. (1996): “The Big Mosaic”. Current Anthropology, 37 (4): 697-699.

RAposo, L. (1993a): “O Paleolítico Médio”. O Quaternário em Portugal - balanço e Perspectivas. Ed. APEQ y Colibri. Lisboa: 147-161.

- (1993b): "O Paleolítico". História de Portugal, vol. 1 - O Começo. Ed. Ediclube. Lisboa: 21-99.

- (1995): "Ambientes, territorios y subsistencia en el Paleolítico Medio de Portugal”. Complutum, 6: 57-77. 
Raposo, L.; Silva, A.C. y Salvador, M. (1985): "Notícia da descoberta da estação mustierense da Foz do Enxarrique (Ródão)". Actas da I Reunião do Quaternário Ibérico, 2: 79-90. Lisboa.

Roche, J. (1971): "Le climat et les faunes du Paléolithique moyen et supérieur de la province d'Estremadura". Actas do II Congresso Nacional de Arqueologia, 1: 39-51. Coimbra.

- (1972): "Faunes du Pléistocène supérieur et final de l'Estremadura, Portugal". Annales de Paléontologie, 58 (2): 229-242. .
Tillier, A.-M. (1982): "Les enfants néanderthaliens de Devil's Tower (Gibraltar)". Zeitschrift für Morphologie und Anthropologie, 73 (2): 125-148. Stuttgart.

Vega Toscano, L.G. (1990): "La fin du Paléolithique moyen au sud de l'Espagne: ses implications dans le contexte de la péninsule ibérique". Mémoires du Musée de Préhistoire d'Ile de France, 3: 169-176. Némours.

- (1993): "El tránsito del Paleolítico Medio al Paleolítico Superior en el Sur de la Península Ibérica". El origen del hombre moderno en el suroeste de Europa. Ed. UNED. Madrid: 147-170.
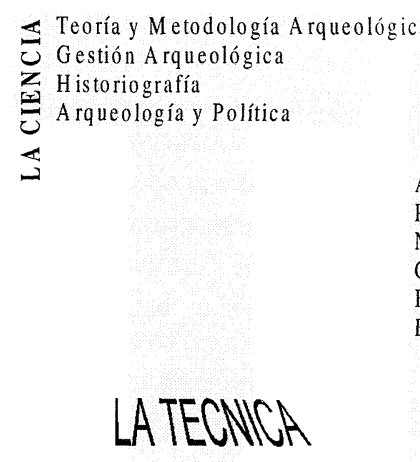

Datación absoluta

A rqueología analític

A rqueom etalurgia

Tecnología experimental

$$
\mathrm{L}^{\mathrm{A}} \mathrm{CULT}_{\mathrm{R}_{\mathrm{A}}}
$$

Arqueología Prehistórica y Protohistórica Paleolítico

Neolítico

Calcolítico

Edad del Bronce

Edad del Hierro

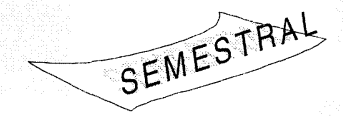

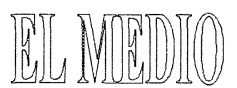

$$
\begin{aligned}
& \text { Arqueobotánica } \\
& \text { A rqueozoología } \\
& \text { Arqueología del Paisaje }
\end{aligned}
$$

Trabajos de Prehis toria es la revista de consulta imprescindible para todos aquellos interesados en conocer el estado de la cuestión sobre el rico patrimonio arqueológico de la Prehistoria y Protohistoria de la Península Ibérica. Sus páginas reflejan tendencias punteras de su especialidad, por lo que figura en los más significativos repertorios bibliográficos nacionales e internacionales.

\section{TRABAJOS DE PREHISTORIA}

(Revista Semestral)

\section{BOLETIN DE PEDIDO

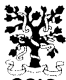 \\ CSIC \\ Servicio de Publicaciones \\ Teléfono: $91 / 5612833$ Fax: $91 / 5629634$
Vitruvio. 8-28006 Madrid (España) \\ Nombre \\ Dirección \\ Ciudad}

Adjunto cheque bancario por valor de............Ptas. a nombre de Servicio de Publicaciones CSIC

Contra reembolso

Envíenme, por favor, factura pro-forma

Tarjeta $\mathrm{V}$ isa $\mathrm{N}^{\circ}$

Fecha de caducidad

T. P., 55, n. ${ }^{\circ} 1,1998$
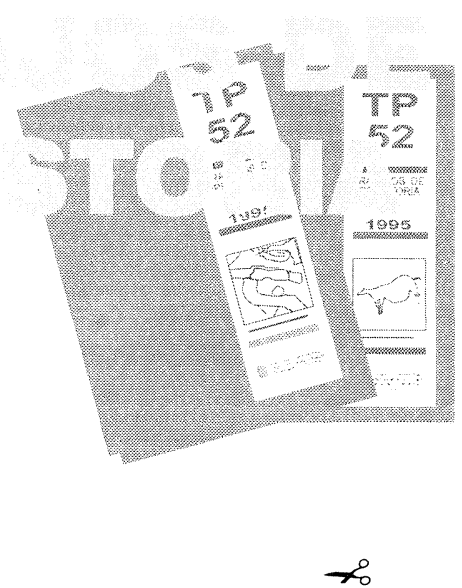